\title{
Racial/Ethnic Matching of Clients and Therapists in Mental Health Services: A Meta-Analytic Review of Preferences, Perceptions, and Outcomes
}

Timothy B. Smith

Brigham Young University, tbs@byu.edu

Raquel R. Cabral

Follow this and additional works at: https://scholarsarchive.byu.edu/facpub

Part of the Counseling Psychology Commons, and the Special Education and Teaching Commons

\section{Original Publication Citation}

Cabral, R., \& Smith, T. B. (in press). Racial/ethnic matching of clients and therapists in mental health services: A meta-analytic review of preferences, perceptions, and outcomes. Journal of Counseling Psychology. http://www.apa.org/pubs/journals/cou/index.aspx

\section{BYU ScholarsArchive Citation}

Smith, Timothy B. and Cabral, Raquel R., "Racial/Ethnic Matching of Clients and Therapists in Mental Health Services: A Meta-Analytic Review of Preferences, Perceptions, and Outcomes" (2011). Faculty Publications. 80.

https://scholarsarchive.byu.edu/facpub/80

This Peer-Reviewed Article is brought to you for free and open access by BYU ScholarsArchive. It has been accepted for inclusion in Faculty Publications by an authorized administrator of BYU ScholarsArchive. For more information, please contact ellen_amatangelo@byu.edu. 
Racial/Ethnic Matching of Clients and Therapists in Mental Health Services: A Meta-Analytic Review of Preferences, Perceptions, and Outcomes

Raquel R. Cabral

Timothy B. Smith

Brigham Young University

Author Note: This manuscript is based on the doctoral dissertation of Raquel R. Cabral, who is now a staff psychologist at St. Edward's University Health \& Counseling Center, Austin, TX. Correspondence concerning this manuscript may be addressed to Timothy B. Smith, Counseling Psychology Dept., Brigham Young University, Provo, UT 84602, email: tbs@byu.edu. 


\begin{abstract}
The effects of matching clients with therapists of the same race/ethnicity have been explored using a variety of approaches across several decades. We conducted a metaanalysis of three variables frequently used in research on racial/ethnic matching: Clients' preferences for a therapist of their own race/ethnicity, clients' perceptions of therapists, and therapeutic outcomes. Across 52 studies of preferences, the average effect size was $d$ $=.63$, indicating a moderately strong preference for a therapist of one's own race/ethnicity. Across 81 studies of individuals' perceptions of therapists, the average effect size was $d=.32$, indicating a tendency to perceive therapists of one's own race/ethnicity somewhat more positively than other therapists. Across 53 studies of client outcomes in mental health treatment, the average effect size was $d=.09$, indicating almost no benefit to treatment outcomes from racial/ethnic matching of clients with therapists. These three averaged effect sizes were characterized by substantial heterogeneity; the effects of racial/ethnic matching are highly variable. Studies involving African American participants demonstrated the highest effect sizes across all three types of evaluations: preferences, perceptions, and outcomes.
\end{abstract}

Keywords: race, ethnicity, culture, psychotherapy, therapeutic alliance 
Racial/Ethnic Matching of Clients and Therapists in Mental Health Services:

A Meta-Analytic Review of Preferences, Perceptions, and Outcomes

Although there is evidence that mental illness is as prevalent among African Americans, Asian Americans, Hispanic/Latino(a) Americans, Native Americans, and Pacific Islander Americans as it is in the White/European American population (Regier et al., 1993; Turner, Lloyd, \& Taylor, 2006), these individuals are less likely than Whites to seek mental health services (Alegría et al., 2008; Gallo, Marino, Ford, \& Anthony, 1995). The 1999 U.S. Surgeon General's Report called for further research to investigate the reasons for the disparities in utilization of mental health services between Whites and people of color. The 2001 U.S. Surgeon General's supplement report found that "racial and ethnic minorities bear a greater burden from unmet mental health needs and thus suffer a greater loss to their overall health and productivity" (p. 3). The concerns expressed in these reports have paralleled a dramatic increase in the number of studies investigating multicultural issues in mental health interventions and associated indications of the importance of increasing multicultural competence among mental health professionals (Ponterotto, Casas, Suzuki, \& Alexander, 2009).

To improve mental health services for people of color, professionals have emphasized the need for cultural congruence between therapists and clients (Pope-Davis, Coleman, Liu, \& Toporek, 2003; Smith, 2009). Matching therapists with clients of the same ethnicity is one aspect of practice that has received sustained attention across several decades (e.g., Møllersen, Sexton, \& Holte, 2009; Sue, Fujino, Hu, Takeuchi, \& Zane, 1991). Much of the research described as ethnic matching consists of studies in which client and therapist share the same racial rather than the same ethnic background. 
Because the term ethnic matching does not accurately represent the type of similarity evaluated most frequently in research, we will refer to the matching of client and therapist based on either race or ethnicity as racial/ethnic matching

\section{Theoretical Basis for Racial/Ethnic Matching}

For several decades, the general presumption has been that matching clients with therapists of the same race/ethnicity should result in stronger therapeutic alliances (Harrison, 1975; Sue, 1977; Sue et al., 1991). This presumption has sound theoretical underpinnings in social psychology. Worldview similarity fosters interpersonal attraction (Byrne, 1971). People tend to be attracted to those who share similar perceived physical attributes (e.g., Berscheid, Dion, Walster, \& Walster, 1971). People typically associate with those they perceive to be similar to themselves (Newcomb, 1961). The application of these well-established tenets to therapy is obvious: clients should tend to prefer therapists who are similar to themselves.

Interpersonal similarity not only influences individuals' preferences for social interactions but also their perceptions of those interactions. Similarity is associated with credibility (Simon, Berkowitz, \& Moyer, 1970). People perceived to be similar to oneself are more likely to be trusted initially than people perceived to be different. Thus perceived similarity with others reduces negative stereotyping (Ames, 2004), but it also increases the likelihood of projecting our own traits onto others (Critcher \& Dunning, 2009). In particular, "people assume greater similarity of opinion between themselves and in-group members than between themselves and out-group members" (Marks \& Miller, 1987, p. 80). In contrast to dyads of different races/ethnicities, clients and 
therapists of the same race/ethnicity should be more likely to trust one another initially and also more likely to assume shared worldviews.

Explanations for how interpersonal preferences and perceptions differ as a function of similarity can be found in a variety of sources. Festinger's (1954) theory of social comparison suggests that we prefer to associate with others who are similar to ourselves for purposes of (self-serving) comparisons, but it is also plausible that we first project assumed similarity onto others who then become points of (self-serving) comparison (Miller \& Marks, 1982). According to theories of consensus bias (i.e., Ross, Greene, \& House, 1977; Marks \& Miller, 1987), people tend to perceive their own judgments as being shared by others and alternative perspectives as being unusual or even unacceptable, such that perceptions of similarity with others are normative when contradictory information is unavailable. People typically presume similarity with others (Robbins \& Kreuger, 2005) unless differences are brought to attention, such as by physical appearance differences across race/ethnicity. In the specific instance of racial/ethnic matching, this means that clients should be likely to assume alignment with therapists of their own race/ethnicity and unlikely to assume alignment with therapists of another race/ethnicity.

If the therapeutic alliance is likely strengthened under conditions of interpersonal similarity, then it stands to reason that client outcomes in therapy should also benefit. Indeed there is some research evidence that similarities in the values of client and therapist predict positive client outcome (Kelly \& Strupp, 1992). Racial/ethnic matching may therefore improve client outcomes by enhancing mutual understanding between client and therapist and by reducing client concerns about being misunderstood or 
mistreated (e.g., Kohatsu et al., 2000). At a more pragmatic level, it seems reasonable that shared social networks and shared community structures may also enhance therapist awareness of accessible resources and sources of support. Thus the client-therapist similarity fostered by racial/ethnic matching could possibly influence psychotherapy outcomes.

However, the reality is that clients and therapists of the same race/ethnicity may be very dissimilar. For instance, a female Korean American therapist raised in Houston may have very little in common with a young man who recently emigrated from Myanmar, although a researcher could technically consider this dyad "matched" on race. Even when therapist and client share ethnic backgrounds, interpersonal differences remain on other variables (socioeconomic status, religion, etc.). Thus a presumption of similarity (based on race alone) may result in disappointment, particularly when client and therapist have incongruous values.

This difference between expected vs. actual similarity could weaken the degree to which meeting clients' preferences for racial/ethnic matching translates into improved therapeutic outcomes. Studies of client preferences tap into projected imagination; potential clients asked by a researcher about their racial/ethnic preferences likely imagine a therapist who also shares their own gender, political opinions, etc. Thus studies of individuals' preferences may blur the issue of racial/ethnic similarity with overall interpersonal similarity.

In any case, the social psychological theories described earlier cannot be taken to the extreme. Perfect similarity of client and therapist is not only impossible but also undesirable; differences in perspectives promote insight, facilitate reframing, etc. 
Although interpersonal similarity may facilitate effective therapy to some degree, racial/ethnic matching has primarily been promoted for reasons related to racism and multicultural competence (cite ). The specific issue requiring confirmation is whether differences based solely on therapist race/ethnicity are sufficient to justify intentional racial/ethnic matching with mental health clients.

Given the clear implications for practice and for training in multicultural competence $(\sim)$, it is important to ascertain the exact magnitude of the effects of racial/ethnic matching. In recent decades the number of empirical studies of racial/ethnic matching in mental health services has increased substantially. These studies have investigated several types of variables, most notably clients' preferences, perceptions, and outcomes. Therefore the remainder of this systematic review specifically attends to (a) individuals' preferences for or against racial/ethnic matching, (b) individuals' perceptions of therapists (i.e., credibility, skill, therapeutic alliance) as a function of racial/ethnic matching, and (c) clients' outcomes in mental health services as a function of racial/ethnic matching.

\section{Previous Literature Reviews}

To date, three meta-analyses (Coleman et al., 1995; Maramba \& Nagayama Hall, 2002; Shin et al., 2005) and several narrative literature reviews (Flaskerud, 1990; Karlsson, 2005; Sattler, 1977; Sue \& Lam, 2002) have summarized the literature on racial/ethnic matching of client and therapist. The largest of these meta-analyses, conducted by Hardin Coleman and colleagues in 1995, included 21 studies conducted between 1971 and 1992. These authors found strong preferences for a therapist of one's own race/ethnicity $(d=.73)$ and a small tendency to perceive therapists of one's own 
race/ethnicity better than others $(d=.20)$. A subsequent meta-analysis by Maramba and Nagayama Hall (2002) involved seven studies conducted between 1977 and 1999. These authors found virtually no effect of racial/ethnic matching on client dropout, number of sessions attended, and level of functioning at termination (Pearson $r$ 's $=-.03,-.04$, and .01 , respectively). Subsequently, Shin and colleagues (2005) summarized ten studies between 1991 and 2001. Data specific to African American clients indicated minimal effects of racial/ethnic matching on drop out, number of sessions attended, and posttreatment functioning ( $d$ 's $=-.19,-.01$, and -.28, respectively).

Thus previous reviews have generally concluded that although people of color prefer therapists of their own race/ethnicity, racial/ethnic matching in therapy does not improve client outcomes. Nevertheless, due to the small number of studies included in previous reviews and the wide variability in the results observed across individual studies, the field could benefit from greater certainty. Some authors doubt the usefulness of ethnic matching (Alladin, 2002; Lambert et al., 2006), while the multicultural psychology literature is open to racial/ethnic matching when practical and nondiscriminatory (e.g., Sue, 1998). Moreover, several questions about the salience of racial/ethnic matching have not yet been addressed. To what degree do the effects of racial/ethnic matching differ across studies of different racial/ethnic groups, including Whites? Does participant age, gender, or level of education moderate the effects of racial/ethnic matching? Have the results of studies changed over time? Fortunately, dozens of research studies have appeared in the literature in recent years. These data necessitate an updated synthesis of contemporary research with specific attention to variables that might moderate the impact of racial/ethnic matching. 


\section{Previous Research on Potential Moderating Variables}

Client race/ethnicity. Given differences in cultural values and mores, it should not be surprising that racial/ethnic matching may not impact all racial/ethnic groups in the same manner. For instance, White/European American clients may implicitly expect to see a therapist of their own race and may therefore initially mistrust a therapist of color, but this possibility has not yet been confirmed. In contrast, research has consistently shown that African American clients tend to mistrust mental health services provided by White/European American therapists (O'Sullivan, Peterson, Cox, \& Kirkeby, 1989; Snowden, 1999; Sue, 1977; Sussman, Robins, \& Earls, 1987). Explanations for this finding include the possibility of a perceived racial bias in the provision of mental health services and the implicit association of mental health services with the values of White/European Americans (Maultsby, 1982; Ridley, 1984). Moreover, racial mistrust among African Americans is moderately associated with their psychosocial functioning (Whaley, 2001). Many studies conducted in previous decades indicated that African American clients benefit from racial/ethnic matching in psychotherapy (Atkinson, 1983, 1985; Griffith \& Jones, 1979, Proctor \& Rosen, 1981; Sattler, 1977; Wolkon, Moriwaki, \& Williams, 1973). However, some subsequent studies have found that racial/ethnic matching was not as crucial for African American clients as previously believed (e.g., Atkinson \& Lowe, 1995). Although conclusions vary somewhat, studies tend to support racial/ethnic matching as being particularly useful for African American clients.

The limited literature investigating the effects of racial/ethnic matching with other racial/ethnic minority groups has yielded mixed results (Karlsson, 2005). For example, 
some evidence indicates that Asian Americans may sometimes prefer White/European American therapists due to internalized racism by Asian Americans (Alvarez \& Helms, 2001). Results of studies of the preference for racial/ethnic matching among Asian Americans have been inconsistent (Atkinson, Maruyama, \& Matsui, 1978; Atkinson \& Matsushita, 1991; Atkinson, Poston, Furlong, \& Mercado, 1989). Similarly, some studies of Hispanic/Latinos(as) indicate a preference for racial/ethnic matching (Lopez, Lopez, \& Fong, 1991; Sanchez \& King, 1986), while others document no preference for matching (Acosta, 1979; Acosta \& Sheehan, 1976; Atkinson, 1983; Sue, Zane, \& Young, 1994). Studies with Native Americans have also generated conflicting results (Atkinson, 1983; Dauphinias, Dauphinias, \& Rowe, 1981; Haviland, Horswill, O’Connell, \& Dynneson, 1983; LaFromboise \& Dixon, 1981). Inconsistency of findings has led some influential scholars to conclude that clients of different racial/ethnic groups should benefit equally from therapy, regardless of whether or not they are racially/ethnically matched with their therapist (i.e., Lambert et al., 2006). It is presently unclear if that conclusion is justified.

Client age, age cohort, gender, and level of education. Client characteristics such as age, gender, and level of education may influence the effects of racial/ethnic matching because these variables are associated with clients' worldviews and experiences. For example, older clients benefit more than younger clients from cultural adaptations in traditional mental health services, presumably because of the association between age and level of acculturation (Griner \& Smith, 2006; Smith, Domenech Rodríguez, \& Bernal, 2011). Exposure to more overt racial/ethnic prejudice over a longer period of time may also make older populations feel more comfortable working with members of their own racial/ethnic group. Nevertheless, several studies have 
demonstrated that even young adult college students prefer therapists of their own race/ethnicity (Atkinson, Furlong, \& Poston, 1986; Atkinson et al., 1989; Haviland et al., 1983; Ponterotto, Alexander, \& Hinkston, 1988; Tharp, 1991). Although there is some indication that adolescents may benefit from racial/ethnic matching (Wintersteen, Mensinger, \& Diamond, 2005), treatment outcomes for children do not appear related to racial/ethnic matching (Gamst, Dana, Der-Karabetian, \& Kramer, 2004).

It is also possible that research findings regarding racial/ethnic matching have changed over time, such that any moderation by client age is confounded with age cohort. Individuals raised in different periods of time have experienced different dynamics of prejudice and discrimination based on race/ethnicity. The incidence of overt discrimination has decreased in recent decades; nevertheless, inequities and microaggressions persist (i.e., Morrison \& Morrison, 2008). Because no longitudinal studies on the topic of racial/ethnic matching have been conducted over a period of decades, only meta-analysis can evaluate whether consistent changes in findings have occurred over time.

Client gender also might moderate the effects of racial/ethnic matching. Previous research findings indicate that men may experience stronger in-group bias than women (Qualls, Cox, \& Schehr, 1992; Ekehammar \& Sidanius, 1982) and that men seek mental health treatment less often than women (Takeuchi \& Cheung, 1998). Indirectly related to racial/ethnic matching, studies of gender matching across racial/ethnic groups have observed benefits for Asian American male clients matched with male therapists, but gender matching was not beneficial for Asian American female clients (Flaskerud \& Liu, 1991) or for African American, Hispanic/Latino(a), or Native American clients (Wu \& 
Windle, 1980). Because so few studies of racial/ethnic matching have examined differences across client gender, we cannot yet ascertain whether males or females benefit more from racial/ethnic matching.

Because level of education is interrelated with level of acculturation to Western society and with attitudes about professional mental health interventions, it may influence the effects of racial/ethnic matching in therapy. Level of education influences not only attitudes about mental health but also the treatment outcomes observed across racial/ethnic groups (Alvidrez, Azocar, \& Miranda, 1996; Atkinson, 1987; Betancourt \& Lopez, 1995; Lorion \& Parron, 1985; Wolkon et al., 1973). Specific evaluations of how level of education may impact racial/ethnic matching have not been conducted previously.

\section{Purpose of Study}

In order to address these complex issues and substantively extend the existing literature, the present study synthesized several times the number of research articles covered by previous literature reviews on racial/ethnic matching. Specifically, our analyses summarized findings relevant to (a) preferences for therapists of individuals' own race/ethnicity, (b) perceptions of therapists across racial/ethnic matching, and (c) outcomes in therapy as a function of racial/ethnic matching. This review also examined several potential moderating variables (e.g., participant age, age cohort, education, gender, race/ethnicity) in order to better understand the dynamics associated with racial/ethnic matching.

\section{Method}




\section{Literature Search}

We reviewed studies included in previous meta-analyses that specifically measured preferences, perceptions, or outcomes. We used several techniques to obtain additional published and unpublished studies that have examined racial/ethnic matching of mental health clients and therapists. First, searches were conducted using the following electronic databases: PsychINFO, Academic Search Elite, Criminal Justice Abstracts, CQ Researcher, Cumulative Index to Nursing and Allied Health Literature (CINAHL), Digital Dissertations, Education Resources Information Center (ERIC) databases, Family and Society Studies Worldwide, Medline, PsycArticles, Social Work Abstracts, Sociological Abstracts, Science Citation Index (SCI), Social Sciences Abstracts, and Social Sciences Citation Index (SSCI). We used four distinct sets of search terms across all databases. The first set included the following specific terms all separated by the Boolean "or" operator (with asterisks indicating inclusion of all terms sharing the word root): "ethnic* match*" or "racial* match*" or "cultural* match*" or "matched on/by ethnicity/race/culture." The second set of search terms consisted of the following: (therapist* ${ }^{*}$ or psychotherapist* or counselor* or therapy or treatment* or intervention*) and (client* or patient*) and ("same race" or "same ethnicity" or "same racial" or "own race" or "own ethnic*" or "own racial"). The third set of search terms included long lists of synonyms (connected with Boolean "or") for five concepts (connected with Boolean “and"): (ethnic* or multicultural* or cross-cultural or cultur* or racial or race* or transcultural or "Native American" or "American Indian" or Hispanic or Latino or Latina or Mexican or Cuban or "African American" or Blacks or Hatian or Asian or Korean or Vietnamese or Japanese or Chinese or "Pacific Islander" or Hawaiian) and (outcome or 
data or subjects or experiment or results or empirical or quantitative or statistic* or study or research or survey or finding* or analy* or method or participants or measure* or assessment* or test* or hypothesis or questionnaire or collect or number* or quantif* or random*) and (counsel* or treatment or guidance or therapy or psychotherapy or session or intake or screening or clinic or service* or interven* or facilitate*) and (match* or discrepancy or differ* or same or corresponding or parallel or equivalent or comparable or similar or alike or like or identical or matrix or varied or combination or equal or diverse) and (prefer* or perceiv* or "own race" or "own ethnic*" or "own racial" or matched or matching). The fourth set of search terms was identical to the third, except that the keyword symbol was applied to each synonym for the terms relevant to ethnicity/race and for the terms relevant to therapy.

The hits resulting from these searches were reviewed initially on the title and then abstract. Online searches were conducted by multiple individuals to reduce errors in how the selection criteria (described below) were implemented. When the online hits appeared to be relevant to racial/ethnic matching in mental health settings, the full manuscripts was reviewed to confirm inclusion. In order to reduce the number of inadvertent omissions, online databases were searched one to three additional times over several years (June, 2003 to March, 2007) for studies published through 2006. A subsequent final search conducted November, 2009 of PsychINFO included studies published through 2008. Data regarding the exact number of online hits and reasons for exclusion were not systematically recorded because that practice was uncommon at the time the searches were conducted; however, the repeated searches of multiple databases over several years 
by multiple individuals provided $\sim$ methodological replication intended to decrease errors of omission.

Reference sections of located articles were examined to identify additional studies that met inclusion criteria. To solicit additional manuscripts, we emailed authors who had published two or more articles on the topic asking them to provide information regarding other (unpublished) studies that could possibly be included in the metaanalysis.

\section{Inclusion Criteria}

Studies that provide quantitative data evaluating individuals' preferences, perceptions, or outcomes relevant to racial/ethnic matching with mental health therapists were included in the meta-analysis. Case studies, single-subject designs, and qualitative research were excluded. We considered all other research designs for inclusion. Studies of individuals' preferences for and perceptions of racial/ethnic matching utilized several research designs, including surveys and analogue research (scenarios created by researchers, such as evaluations of videotaped mental health services provided in matched and unmatched conditions). We restricted studies of treatment outcomes as a function of racial/ethnic matching to clients receiving mental health services provided by therapists with some graduate training.

Our review was intended to broadly address the issue of racial/ethnic match, so we included all research in which the client-therapist combinations evaluated were exclusive to race/ethnicity, irrespective of the particular race/ethnicity involved. Thus pertinent data with White/European Americans were included, and our analytic strategy provided for the disaggregation of results by race/ethnicity. 
Because at least two members of the research team were fluent in both English and Spanish (but not other languages), we initially considered all manuscripts written in those two languages (but not others). By the end of our review, however, we had failed to identify relevant manuscripts written in Spanish, so we used exclusively English during data coding.

\section{Data Coding}

Graduate and undergraduate research assistants, most with previous experience in meta-analytic coding, received training and supervision specific to this meta-analysis. Coding teams of two members each verified the accuracy of coding and data entry. Two teams reviewed every article. Coders extracted independent and identifiable characteristics from each study, including the publication year and manuscript type (journal article or dissertation/thesis), along with the number of participants and their age, gender, race/ethnicity, and years of education.

Adequate inter-rater agreement was obtained for categorical variables (average Cohen's Kappa value of .78) and for continuous variables (average intraclass correlation value of .96 using one-way random effects models for single measures). Discrepancies across coding teams were resolved through further scrutiny of the manuscript to the point of consensus among coders.

\section{Computation of Effect Size Estimates}

Among the studies included in this meta-analysis, several different statistics were reported: correlations, analyses of variance, $t$-tests, odds ratios, chi squares, means and standard deviations, and $p$-values. In order to compare these data across studies, the statistics reported were transformed to standardized mean differences (Cohen's $d$ ) using 
the Meta-analysis Calculator software (Lyons, 1996). If an analysis was reported to be "statistically significant" but no statistic was provided, the $d$ value was determined by the corresponding alpha level (assuming two-tailed alpha $=.05$ unless reported otherwise). Analyses that reported results as "non-significant" but gave no additional information were set to effect size $d=.00$. These procedures help yield conservative effect size estimates. The directions of all effect sizes were coded uniformly on a continuous scale, such that positive values indicated a comparatively greater preference for or benefit from racial/ethnic matching and negative values indicated a disinclination for or reduced benefit from racial/ethnic matching.

Several studies contained data that were pertinent to more than one of the three variables evaluated in this review (preference, perception, and outcome). These three different types of data were handled separately. For instance, if a study contained data pertinent to both client perceptions and client outcomes, those two types of data were analyzed apart from one another.

In some cases, studies contained multiple effect sizes pertinent to one type of variable being analyzed. For example, some studies assessed several aspects of client symptom reduction (i.e., anxiety and depression). According to the assumption of statistically independent samples, there would be a greater likelihood of nonindependence in the data should every effect size be used within an omnibus analysis (Cooper, 1998; Cooper \& Hedges, 1994; Hedges \& Olkin, 1985). Therefore, multiple effect sizes within studies were averaged (weighted by the number of participants included in the analysis) to compute an aggregate effect size (Mullen, 1989). For instance, if a study contained two effect sizes pertinent to client perceptions and four 
effect sizes pertinent to client outcomes, the two effect sizes were aggregated to obtain a single estimate of client preferences and the four effect sizes were aggregated to obtain a single estimate of client outcomes. Thus any given study contributed only one data point to the distinct analyses of preferences, perceptions, and outcomes.

\section{Data Analyses}

Because the results of this meta-analysis were intended to generalize beyond the studies located and because the effects of racial/ethnic matching were presumed to vary across different client and intervention characteristics, random effects models were used in all analyses (Field, 2005). Analyses were conducted using SPSS macros developed by Lipsey and Wilson (2001).

Data were analyzed separately to evaluate preferences for racial/ethnic matching, perceptions of therapists as a function of racial/ethnic matching, and outcomes in therapy as a function of racial/ethnic matching. The obvious differences in these three types of data clearly warranted distinct evaluation in the present review. When a study contained data across more than one of these three categories, effect sizes were disaggregated accordingly. For instance, an effect size pertaining to clients' perceptions of therapists was analyzed separately from effect sizes in the same study pertaining to client outcomes.

Effect sizes specific to individuals' preferences for or against racial/ethnic matching were typically derived from the differences between rated preferences for a therapist of participants' own race/ethnicity and rated preferences for a therapist of any other race/ethnicity. However, a few studies asked directly for participants' preferences for racial/ethnic matching in absolute rather than comparative terms. For these studies, the effect size was calculated from the difference between participants' preferences for a 
therapist of their own race/ethnicity and the neutral rating that indicated no preference for therapist race/ethnicity.

Effect sizes specific to perceptions of therapists as a function of racial/ethnic matching were calculated based on the differences between the evaluations provided for therapists of the participants' own race/ethnicity and those provided for therapists of any other race/ethnicity. Effect sizes specific to clients' outcomes consisted of the statistical differences between the outcomes (i.e., symptom reductions) reported with clients matched with a therapist of their own race/ethnicity and clients who had a therapist of another race/ethnicity.

\section{Results}

\section{Descriptive Information}

A total of 154 studies were located that met inclusion criteria. Across these studies, 52 contained effect sizes specific to participant preferences for therapist racial/ethnic match, 81 contained effect sizes specific to participant perceptions of therapists as a function of racial/ethnic match, and 53 contained effect sizes specific to client outcomes as a function of therapist racial/ethnic match. Table 1 contains descriptive information broken down by these three categories of data. The type of data analyzed within each manuscript is identified in the reference section of this manuscript.

Studies evaluating preferences for therapist racial/ethnic match typically involved surveys administered to non-clinical populations, most often college students. We found a tendency for such studies to have been conducted more often in previous decades than in the recent past. Participants in these studies typically provided preference ratings for a 
hypothetical future therapist based on race/ethnicity — or rated their levels of perceived self-disclosure or comfort across therapists of different races/ethnicities.

Many studies of perceptions of therapists as a function of racial/ethnic match presented hypothetical situations eliciting evaluations of therapists matched or not by race/ethnicity. About equally as often these studies compared the ratings of therapists by clients who had vs. did not have a therapist of the same race/ethnicity (which we termed a "group comparison" in Table 1). Across perception studies, ratings typically involved the Counselor Effectiveness Rating Scale (Atkinson \& Carskaddon, 1975), the Counselor Rating Form (Barak \& LaCrosse, 1975), and similar evaluations of therapist traits and skills.

Studies of clinical outcomes compared clients who had received treatment with a therapist of their own race/ethnicity vs. those who had received treatment from a therapist not of their own race/ethnicity. We found a tendency for those studies to have been conducted relatively recently, with half of them appearing during the previous decade. Some of these studies used archival data and others used prospective designs, but both involved essentially the same comparison of naturally occurring (non-randomized) racial/ethnic matching of client and therapist. Outcome studies commonly occurred in community clinics, college counseling centers, or inpatient mental health facilities.

Client symptoms were measured by instruments such as the Outcome Questionnaire-45 (Lambert et al., 1996) and the Global Assessment of Functioning (American Psychiatric Association, 2000).

\section{Omnibus Analyses}


Across the 52 studies investigating participants' preferences for therapist race/ethnicity, the random effects weighted average effect size was $d=.63$ (SE $=.08, \mathrm{p}<$ $.001,95 \% \mathrm{CI}=.48$ to .78$)$, indicating a moderately strong preference for a therapist of the same race/ethnicity. Across the 81 studies investigating client perceptions of therapists as a function of racial/ethnic matching, the random effects weighted average effect size was $d=.32(\mathrm{SE}=.07, \mathrm{p}<.001,95 \% \mathrm{CI}=.19$ to .45$)$, indicating a tendency for participants to evaluate matched therapists somewhat better than unmatched therapists. Across the 53 studies investigating client treatment outcomes under matched vs. unmatched conditions, the random effects weighted average effect size was $d=.09$ $(\mathrm{SE}=.02, \mathrm{p}<.001,95 \% \mathrm{CI}=.05$ to .13$)$, indicating almost no difference in outcome when clients were matched with a therapist of their own race/ethnicity.

Effect size heterogeneity was substantial across all three categories of data. Among preference studies, effect sizes ranged from -.24 to 3.35 , with $90 \%$ of the variability attributable to between-study differences $\left(I^{2}=90 ; Q_{(51)}=509, p<.001\right)$. Among perception studies, effect sizes ranged from -1.10 to 3.49 , with $90 \%$ of the variability attributable to between-study differences $\left(I^{2}=90 ; Q_{(80)}=776, p<.001\right)$. Among outcome studies, effect sizes ranged from -.55 to 1.78 , with $82 \%$ of the variability attributable to between-study differences $\left(I^{2}=82 ; Q_{(52)}=295, p<.001\right)$. Systematic effect size variability remained unaccounted for in all three analyses. Subsequent analyses were conducted to determine the extent to which the variability of the effect sizes was moderated by other variables.

\section{Analyses to Evaluate Possible Publication Bias}


We evaluated the possibility that the results were moderated by the publication status of the research manuscript. In meta-analyses, publication bias is related to (a) the likelihood for meta-analyses to include larger numbers of published than unpublished studies and (b) the likelihood for published studies to have larger effect sizes than unpublished studies. The combination of these two trends may result in a meta-analysis reporting inflated effect size values unless publication bias is explicitly evaluated.

As a first step to rule out the possibility of publication bias, we calculated Orwin's (1983) fail-safe $N$, the theoretical number of unpublished/missing studies with effect sizes averaging zero (no effect) that would reduce the overall results obtained to a trivial magnitude. These calculations indicated that 397 additional preference studies, 170 additional perception studies, and 48 additional outcome studies would need to be located with average effect sizes of $d=0$ to render negligible the results obtained. These values suggest that publication bias is unlikely for studies of client preferences and perceptions, but publication bias could not be ruled out for the studies of client outcome because it is conceivable that 48 additional outcome studies could have remained missing from our analyses.

For the next step we plotted the effect sizes against the standard error of each study, often referred to as a funnel graph (Begg, 1994). The data generally conformed to the expected distribution, but several studies failed to fall within the typical range, possibly indicating "missing" studies on the opposite side of the distribution. Therefore, as a final step we conducted a "trim and fill" analysis (Duval \& Tweedie, 2000) to estimate the number of missing studies due to publication bias. In the current study, the recalculated random effects weighted mean effect sizes remained the same across all 
three data categories (preference, perception, and outcome) because no studies met the statistical criteria to be "trimmed" from the analyses. Thus publication bias did not appear likely to be a threat to the results obtained in this meta-analysis.

\section{Moderation by Participant and Study Characteristics}

Given the high degree of effect size heterogeneity observed, we examined whether the omnibus values reported above were moderated by participant and study characteristics relevant to racial/ethnic matching. Because differences across participant race had been observed in previous research (Karlsson, 2005), we first analyzed the data by client race/ethnicity. Effect sizes within studies that were specific to Asian Americans, African Americans, Hispanic/Latino(a) Americans, and White/European Americans were contrasted with one another. As shown in Table 2, statistically significant differences were apparent across all three categories of data (preferences, perceptions, and outcomes). The relevance of racial/ethnic matching was greatest among African American participants, the only group with effect sizes statistically different from zero for all three analyses. Their preferences for therapists of their own race/ethnicity were very strong; their perceptions of therapists varied substantially as a function of racial/ethnic matching; and their outcomes in therapy tended to be mildly better when their therapist was African American. In contrast, racial/ethnic matching was apparently least relevant to White/European Americans; none of the three effect sizes statistically differed from zero. The results with Asian American and Hispanic/Latino(a) Americans were mixed. Asian Americans showed only mild preferences for a therapist of their own race/ethnicity but tended to provide more positive evaluations for therapists of their own race/ethnicity. Conversely, Hispanic/Latino(a) American participants expressed 
moderately strong preferences for a therapist of their own race/ethnicity but did not evaluate therapists differently based on race/ethnicity.

We next evaluated the degree to which effect sizes were associated with the year of study publication (to evaluate possible changes over time), average participant age, average years of participant education, percentage of female participants in the sample, and estimated average year of participant birth (year of study minus average age of client as an estimate of cohort effects). Random effects weighted correlations were conducted between the values obtained on those variables and the effect size for each study. As displayed in Table 3, most correlations were of small magnitude, suggesting that none of the participant variables moderated the data. The only correlation to reach statistical significance was the year of publication of preference studies $(r=-.29, p=.04)$. The earlier the year of the study, the stronger the preference expressed for racial/ethnic matching. To evaluate only relatively recent results, we re-calculated the average random effects weighted effect size for the eight studies that have appeared since the year 2000 . The resulting value of $d=.49(95 \% \mathrm{CI}=.07$ to $.90, p=.02)$ indicated that, on average, preferences for a therapist of one's own race/ethnicity still existed in the most recent decade but were of moderate magnitude.

Studies of individuals' perceptions of therapists included both analogue studies and studies of actual clients receiving services, so it was important to distinguish whether differences in the results would be found across those conditions. The average random effects weighted effect size was $d=.46$ for analogue studies with hypothetical scenarios but $d=.20$ for studies involving clients' evaluations of their own therapist, which difference was statistically significant $(Q=4.3, p=.04)$. Thus the overall effect size 
reported previously for perception studies was moderated by the research procedures used. Racial/ethnic matching was less relevant to the perceptions of therapists by actual clients than to individuals considering scenarios presented by researchers.

Studies of client outcomes in therapy included both prospective and retrospective (archival) designs. The results obtained across these two procedures were not statistically different $(Q=1.6, p>.05)$.

\section{Discussion}

Enhancing client-therapist similarity should increase mutual understanding and strengthen the therapeutic alliance, with associated benefits to client outcomes in therapy. Nevertheless, the data indicate that mental health treatment outcomes do not substantively differ when clients do or do not have a therapist of their same race/ethnicity. "Match is neither a necessary nor a sufficient condition for positive treatment outcomes. In other words, match may be important for some, but not all, clients" (Sue, 1998, p. 444).

One explanation for the results of the outcome research could hypothetically involve differential experimental attrition if dissimilar client-therapist dyads are susceptible to premature termination (such that client outcomes erroneously appear unaffected by racial/ethnic matching). This possibility has not been verified in previous reviews (Maramba \& Nagayama Hall, 2002; Shin et al., 2005) but could benefit from future confirmation. Another explanation involves the multiple influences of interpersonal similarity: Even though perceived similarity reduces negative stereotyping, it increases consensus bias (Ames, 2004), the assumption of greater similarity than actually exists. Perceived similarity is independent of actual self-other agreement (Kenny 
\& West, 2010); individuals make inaccurate assumptions about how similar they are to others. Specifically, people of the same race/ethnicity may not share the same worldview, and people of different races/ethnicities may have compatible worldviews. There is greater variability within racial/ethnic groups than individuals typically conjecture. Moreover, categorical conceptualizations of race/ethnicity do not account for related variables such as level of client inter-racial mistrust or therapist multicultural competence. Race/ethnicity is too imprecise and too complex to consistently impact averaged therapy outcomes.

One interpretation of the data from this meta-analysis is that racial/ethnic matching of client and therapist are more relevant to the cognitive heuristics of preferences for and perceptions of therapists than to the average effectiveness of therapy. In general, individuals tend to prefer having a therapist of their own race/ethnicity (who they likely imagine would share their own worldview), but once they enter a therapeutic relationship, the therapists' race/ethnicity makes only a little difference in how positively they evaluate the therapist and makes virtually no difference in how much they benefit from the treatment provided. These results, based on a substantial number of studies, are consistent with those of previous meta-analyses and reviews using far fewer studies (Coleman et al., 1995; Flaskerud, 1990; Karlsson, 2005; Maramba \& Nagayama Hall, 2002; Shin et al., 2005; Sue \& Lam, 2002). Nevertheless, the heterogeneity of the effect sizes in our review qualifies the degree to which the findings can be generalized.

The notable exception to the overall findings concerns African Americans. On average, African Americans very strongly preferred to be matched with African American therapists. They tended to evaluate African American therapists more 
positively than other therapists. Their outcomes in therapy appeared to be mildly better when they were matched with African American therapists. Factors responsible for these findings likely include strong racial/ethnic identification and wariness about bias in the mental health services provided by White therapists (e.g., Ridley, 1984; Snowden, 1999).

The finding that client race/ethnicity moderated preferences, perceptions, and outcomes is not surprising (Griffith \& Jones, 1979; Lopez, Lopez, \& Fong, 1991; Proctor \& Rosen, 1981; Sattler, 1977; Wolkon, Moriwaki, \& Williams, 1973). Our results confirm that racial/ethnic matching is more salient for people of color than for White/European Americans, as would be expected (Sue, 1998). Moreover, the results of this meta-analysis clarify some mixed results noted in previous studies (i.e., Atkinson, 1983; Atkinson, Maruyama, \& Matsui, 1978; Karlsson, 2005). Although Asian Americans may not express strong initial preferences for a therapist based on race, they appear to perceive Asian American therapists more positively than other therapists. The opposite trend was noted for Hispanic/Latino(a) Americans, whose expressed preferences for therapists of the same ethnic background were strong, but whose evaluations of therapists differed only slightly as a function of racial/ethnic match.

Overall, the pattern of different findings across the three types of variables (preference, perception, and outcome) can be explained in part by the nature of those variables. Client preference for therapist race/ethnicity is the most straightforward variable: It directly measures client attitudes about matched therapists (albeit likely confounded by implicitly imagining someone of similar age, gender, etc.). By comparison, perceptions of therapists are more complicated: Many factors other than race/ethnicity enter into the equation, including variables more relevant to the 
evaluations, such as therapist skills and dispositions. Client outcome is by far the most complicated variable, with dozens if not hundreds of factors impacting it, only some of which would relate to therapist characteristics. Thus the effect of racial/ethnic matching appears to be diminished as more variables become involved. Common factors are more predictive of client outcome than specific treatment variables (Messer \& Wampold, 2002), including therapist race/ethnicity. This interpretation is consistent with Stanley Sue's (1988) observation that "ethnicity of therapist or client and ethnic match are distal variables; consequently, weak or conflicting results are likely to be found between ethnic match and outcome" (p. 306).

We therefore encourage inquiry into variables more directly relevant to therapist alignment with client worldviews (i.e., therapist multicultural competence, congruence of therapist and client racial identity status, interracial mistrust) that may further increase the amount of variance explained in client outcomes (APA, 2003; Arredondo \& Perez, 2006). Racial/ethnic matching is a proxy variable for worldview matching (e.g., Zane et al., 2005). More than two decades after Sue and Zane's (1987) proposal to shift the focus from distal to proximal variables in research involving race/ethnicity, that advice still seems cogent. Future research can ascertain the specific mechanisms through which proximal variables (i.e., interpersonal trust, cognitive adaptability, shared linguistic parlance) help to improve treatment outcomes now that we understand the specific magnitude of the effect of racial/ethnic matching. 


\section{Limitations of the Meta-Analyses}

Meta-analytic methods, like all other research methods, have limitations. Although the majority of the limitations of this particular meta-analysis are minor, several warrant further discussion.

First, substantial heterogeneity was found in the effect sizes obtained across all three categories of data (preference, perception, and outcome). Interpreting only the averaged findings masks the variability between studies. For instance, although most studies documented a preference for having a therapist of one's own race/ethnicity, several studies uncovered preferences for therapists of another race/ethnicity. Thus the omnibus results lack precision and should be considered as broad trends, rather than conclusive predictors of individuals' responses.

Second, the quality, methodology, and research design of each individual study included in the meta-analysis influence the overall results of any meta-analysis (Cooper, 1998; Cooper \& Hedges, 1994; Matt \& Navarro, 1997; Quintana \& Minami, 2006). There are presently too few studies using experimental designs (see Table 1) for us to have complete confidence in the findings. Random assignment of participants to matched vs. unmatched conditions would be essential to control for possible systematic biases, including the differential selection of participants to those conditions (Campbell \& Stanley, 1966). Future summaries of research using true experimental designs may yield more reliable results that those presented in this meta-analysis.

Third, most of the evaluations of individuals' preferences for therapist race/ethnicity involved hypothetical scenarios (if they were to seek mental health services). Most of those participants were not mental health clients, so the results of the 
preference studies reflect preferences of the general public more than those of individuals actually seeking treatment. There is reason to suspect that the results would differ across those two populations; for instance, false consensus bias is stronger in laboratory settings than in actual interpersonal interactions (Robbins \& Krueger, 2005). Our analyses with perception data indicated that clients in therapy evaluated their own therapists less as a function of racial/ethnic matching than did individuals not in therapy who evaluated hypothetical scenarios presented by researchers. Overall, it seems highly likely that studies involving hypothetical therapists share a major confound: people who imagine a therapist of their own race/ethnicity probably also imagine someone of their own age, gender, sexual orientation, etc. Thus hypothetical scenarios likely confuse the effects of shared race/ethnicity with overall interpersonal similarity.

Fourth, we did not re-calculate the effect size estimates within studies based on the procedures described by Gleser and Olkin (1994) . Such procedures would have more accurately accounted for interdependence among the estimates, but they require estimates of the correlations among the measures used within studies, which information was unavailable in the vast majority of manuscripts. Although default values such as .50 are sometimes used, we preferred to maintain a straightforward procedure at the expense of some statistical precision.

Fifth, the studies located for the meta-analyses were all written in English, with only a few of the studies conducted outside North America. Even though the participants were from a variety of different racial/ethnic groups, they were almost all North American. Thus the results of our review do not represent research findings outside 
North America or even populations in North America with low levels of acculturation, such as first generation immigrants.

\section{Implications for Future Research}

Despite evaluating therapists of one's own race/ethnicity more positively than those of dissimilar backgrounds, clients (and therapists) appear to be able to negotiate apparent differences such that the outcomes experienced in therapy are minimally impacted. Clients benefit from therapy despite their initial preferences being unmet and their evaluations of therapists' traits and skills being somewhat affected. By implication, the greatest relevance of racial/ethnic matching occurs prior to therapy and during the initial sessions of therapy when the therapeutic alliance is being formed. For instance, clients who enter therapy with a therapist of another race/ethnicity may presume worldview dissimilarity and thus be pleasantly surprised when it does not occur. Oppositely, clients who specifically request a therapist of their own race/ethnicity but then encounter divergent worldviews with a therapist of their same race/ethnicity may have unmet expectations detrimental to the therapeutic alliance. Future research can more specifically investigate the processes by which clients and therapists interact in similar vs. dissimilar dyads (e.g., Sue, 1988).

Given that individuals project their own worldview onto others (Critcher \& Dunning, 2009), particularly on the values central to their own identity (Lee et al., 2009), a specific hypothesis in need of confirmation is that the more salient race/ethnicity is to the client and/or therapist, the more relevant racial/ethnic matching becomes in psychotherapy. Future research on the interaction between racial/ethnic matching and strength of client and therapist racial/ethnic identification and identity status appears 
warranted. For instance, people whose social circles are restricted to their own group may have strong preferences for racial/ethnic matching (i.e., selective exposure; Marks \& Miller, 1987), whereas those who regularly interact with out-groups may experience diminished projection (Robbins \& Krueger, 2005) and lessened relevance of racial/ethnic matching in therapy.

The discrepant findings between clients' outcomes and their preferences for and perceptions of therapists that were observed in the meta-analytic data may be partially explained by service utilization and retention rates. Possible people of color who are willing to negotiate cross-cultural differences are those who actually come to services and those who persist in receiving services. Their preferences and perceptions may indirectly influence the likelihood of their utilizing mental health services and the likelihood of their remaining engaged in those services (Zane et al., 2005). In contrast, clients who experience discomfort across racial/ethnic differences may be less likely to attend and more likely to drop out of therapy. Hence the small magnitude of the effect sizes of client outcomes could partially reflect experimental selection bias and differential attrition (Campbell \& Stanley, 1966). To control for these possible confounds, future research should randomly assign clients to matched vs. unmatched conditions and explicitly account for attrition.

An interesting finding suggested the possibility of a shift over time in client preferences, with recent studies demonstrating preferences of lower magnitude compared with studies conducted in previous decades. One possible explanation for this apparent trend relates to changes in the social and political climates in North America (Arredondo \& Perez, 2006; Choma \& Hodson, 2008). Although there is strong evidence that racism 
persists in contemporary society, explicit racial tension with overt oppression was more characteristic of the previous century (Dovidio, 2001; Dovidio, Gaertner, Kawakami, \& Hodson, 2002). Clients in earlier decades may have sought out therapists of their own race/ethnicity to mitigate the possibility of discriminatory treatment (e.g., Whaley, 2001). It is also possible that clients from historically disadvantaged backgrounds have become more informed about mental health services over time, with reduced client anxiety and negative expectations about treatment, or that therapists have become more competent in working with clients of dissimilar race/ethnicity due to multicultural training required in accredited graduate programs (Smith et al., 2006).

Overall, the results of this meta-analysis confirm trends previously recognized in the literature. However, they do not speak to the more pressing issues of causality and utility. To what degree are differences in clients' evaluations of therapists across matched vs. unmatched conditions attributable to therapists' biases or levels of multicultural competence? Under what conditions do dissimilarities in values/worldviews with therapists help clients? What specific variables influence the differential perceptions of therapists observed across client race/ethnicity? Questions such as these that go beyond a binary formulation of racial/ethnic matching would help to promote more effective mental health services (Nagayama Hall, 2001).

As suggested by Zane and colleagues (2005), future research would more productively focus on the notion of worldview or cognitive matching rather than matching by the more distal variable of race/ethnicity. This line of research is not new (Mendelsohn \& Geller, 1963), but it may have languished over the years because of the additional effort required to measure both therapists' and clients' worldviews rather than 
merely assume similarities (Nagayama Hall, 2001). Future research should attend to matching clients with therapists who accurately articulate and value the clients' conceptualization of well-being and dysfunction, mechanisms for coping, and desired goals for treatment (Smith, 2009). Attending to common factors (Messer \& Wampold, 2002) and components of therapy that are amenable to intervention, like therapist communication skills, would seem to be constructive areas for exploration (see Sue, 1998). Optimally this work would be conducted in clinical settings, given the differences identified in this review between clinical and analogue research.

\section{Implications for Practice}

Even though we live in a multicultural society, with greater diversity than ever before, the practice of matching clients with therapists of the same race/ethnicity is not often feasible. Moreover, if agencies were to adopt rigid policies about matching clients with therapists of the same racial/ethnic background, unintended negative consequences might result (Alladin, 2002). Therapists and/or clients might feel segregated; therapists working primarily with a single population could fail to develop cross-cultural skills; treatment might minimize other meaningful differences such as gender orientation; and treatment might fail to acknowledge that within-group differences can be larger than between-group differences. And there are significantly fewer therapists of color than would be necessary to systematically implement racial/ethnic matching (APA, 2005). Concisely stated, "Psychotherapy for ethnic minorities is not simply an issue for ethnic minority persons" (Nagayama Hall, 2001, p. 508).

The results of this meta-analysis suggest that therapists who work with clients of another race/ethnicity can be optimistic rather than fearful; client outcomes are generally 
unaffected by therapist race/ethnicity. Nevertheless, the results do suggest that therapists need to apply multicultural competencies (Sue, Arredondo, \& McDavis, 1992) to foster positive client preferences and perceptions, particularly when working with African American clients. The experiences and perceptions of African American clients significantly differ when they have a therapist of their same race vs. another race. This difference must be addressed. For instance, professional training programs may benefit from an enhanced focus on the experiences and worldviews of African Americans to enable therapists from other backgrounds to provide culturally congruent mental health services.

The data from this meta-analysis also suggest that therapists should not naively believe that all clients are alike (i.e., Neville, Spanierman, \& Doan, 2006). The research findings showed substantial variability. This does not suggest that race/ethnicity does not matter for a client, but rather that racial/ethnic dynamics are so complex that prediction is problematic. Individuals' experiences with race/ethnicity must be acknowledged more than aggregate trends. Therapists who acquire multicultural awareness, knowledge, and skills can work with both similarities and differences to enhance the therapeutic alliance.

The focus of cross-cultural mental health interventions needs to remain on issues of effectiveness (Sue, 1998), attending to factors that directly influence clients' utilization, retention, and outcome in mental health services. Rather than continue to debate the utility of racial/ethnic matching, researchers and practitioners should place primary emphasis on modifying treatments to match clients' worldviews (Benish, Quintana, \& Wampold, 2011; Smith, 2009; Smith et al., 2011), therapist multicultural 
competence (Arredondo \& Perez, 2006; D.W. Sue et al., 1992), and professional skills development (Cates, Schaefle, Smaby, Maddux, \& LeBeauf, 2007; Smith et al., 2006).

\section{Conclusion}

For decades, psychologists have rightly been concerned about reducing negative stereotyping and increasing positive outcomes of clients whose race/ethnicity differs from that of the therapist (e.g., Ridley, 1984). Matching clients with therapists of their own race/ethnicity has been one strategy for doing so that has been increasingly been overtaken by more practical alternatives, such as the provision of effective multicultural training (Smith et al., 2006). The data summarized in the present meta-analysis indicate that although people prefer to have a therapist of their own race/ethnicity and tend to perceive therapists of their own race/ethnicity somewhat more positively than others, their improvement in treatment is largely independent of therapist race/ethnicity.

Nevertheless, these averaged findings mask a high degree of variability in the research data; racial/ethnic matching yields inconsistent results. In particular, African Americans and individuals with strong racial/ethnic preferences or mistrust may benefit from being matched with a therapist of their own race/ethnicity. So long as group biases persist in society (e.g., Morrison \& Morrison, 2008), racial/ethnic matching will remain relevant to mental health services with discriminated and misunderstood populations.

Overall, we believe that it is past time to adopt refined conceptualizations of racial/ethnic dynamics in therapy (e.g., Sue \& Zane, 1987) that include proximal variables such as perceived similarity vs. actual similarity. Social psychology has moved past basic tenets about similarity in interpersonal settings (e.g., Berscheid et al., 1971; Byrne, 1971; Newcomb, 1961; Ross et al., 1977; Simon et al., 1970) with theoretical 
models and empirical research that have become increasingly complex (i.e., Ames, 2004; Kenny \& West, 2010). If the next generation of applied studies of racial/ethnic matching better account for this complexity, we have reason to suspect that mental health services can be improved by enhancing the alignment of those services with client racial/ethnic worldview (Benish et al., 2011; Smith et al., 2011). 


\section{References}

References preceded by numerals indicate inclusion in the analyses of preferences (1), perceptions (2), and/or outcomes (3).

${ }^{2}$ Abbot, K., Tollefson, N., \& McDermott, D. (1982). Counselor race as a factor in counselor preference. Journal of College Student Personnel, 23, 36-40.

${ }^{1}$ Abreu, J. M. (2000). Counseling expectations among Mexican American college students: The role of counselor ethnicity. Journal of Multicultural Counseling and Development, 28, 130-143.

${ }^{1}$ Abreu, J. M., \& Gabarain, G. (2000). Social desirability in Mexican-American counselor preferences: Statistical control for a potential confound. Journal of Counseling Psychology, 47(2), 165-176.

Acosta, F. X. (1979). Preferences and self-disclosure in relation to psychotherapist professional and ethnic identification. Journal of Psychology, 103, 129-134.

Acosta, F. X., \& Sheehan, J. G. (1976). Preferences toward Mexican American and Anglo American psychotherapists. Journal of Consulting and Clinical Psychology, 6, 545-553.

${ }^{2}$ Acosta, F. X., \& Sheehan, J. G. (1978). Self-disclosure in relation to psychotherapist expertise and ethnicity. American Journal of Community Psychology, 6(6), 545553.

${ }^{2}$ Adair, R. G. (1972). The effects of counselor-client differences in race on Black clients' anticipation and perception of counselor behavior. (Unpublished doctoral dissertation). Auburn University, Auburn, AL. 
${ }^{2}$ Adams C. L. (1981). The influence of counselor race, attire, and speech style on black juvenile delinquents' perception of counselor attractiveness and ability to be warm, empathic, and genuine. (Unpublished doctoral dissertation). University of Notre Dame, Notre Dame, IN.

${ }^{1}$ Agostini, H. E. (1975). Ethnic variables in preference for psychotherapists. (Unpublished doctoral dissertation). Adelphi University, Garden City, NY.

${ }^{2,3}$ Aguilar-Kitibutr, A. (2004). Effects of consumer-modal provider ethnic match, ethnicity, acculturation, and ethnic identity on treatment outcomes and satisfaction of child and adolescent consumers. (Unpublished doctoral dissertation). University of La Verne, La Verne, CA.

Alegría, M., Chatterji, P., Wells, K., Cao, Z., Chen, C., Takeuchi, D., Jackson, J., Meng, X. (2008). Disparity in depression treatment among racial and ethnic minority populations in the United States. Psychiatric Services, 59(11), 1264-1272.

Alladin, W. (2002). Ethnic matching in counselling: How important is it to ethnically match clients and counselors? In S. Palmer (Ed). Multicultural counselling: A reader (pp. 175-180). Thousand Oaks, CA: Sage.

Alvarez A., \& Helms, J. (2001) Racial identity and reflected appraisals as influences on Asian Americans' racial adjustment. Cultural Diversity and Ethnic Minority Psychology, 7(3). 217-231.

Alvidrez, J., Azocar, F., \& Miranda, J. (1996). Demystifying the concept of ethnicity for psychotherapy research. Journal of Consulting and Clinical Psychology, 44, 272279. 
American Psychiatric Association. (2000). Diagnostic and statistical manual of mental disorders. (4th ed., Rev.) Washington, DC: Author.

American Psychological Association. (2003). Guidelines on multicultural education, training, research, practice, and organizational change for psychologists. American Psychologist, 58(5), 377-402.

American Psychological Association. (2005). APA presidential task force on enhancing diversity: Final report. American Psychological Association Office of Ethnic Minority Affairs.

Ames, D. (2004). Strategies for Social Inference: A Similarity Contingency Model of Projection and Stereotyping in Attribute Prevalence Estimates. Journal of Personality and Social Psychology, 87(5), 573-585.

Arredondo, P., \& Perez, P. (2006). Historical perspectives on multicultural guidelines and contemporary applications. Professional Psychology: Research and Practice, $37(1), 1-5$.

Atkinson, D. R. (1983). Ethnic similarity in counseling psychology: A review of research. The Counseling Psychologist, 11, 79-92.

Atkinson, D. R. (1985). A meta-review of research on cross-cultural counseling and psychotherapy. Journal of Multicultural Counseling and Development, 13(4). $138-153$. 
Atkinson, D. R. (1987). Counseling Blacks: A review of relevant research. Journal of College Student Personnel, 28, 552-558.

Atkinson, D. R., \& Carskaddon, G. (1975). A prestigious introduction, psychological jargon, and perceived counselor credibility. Journal of Counseling Psychology, $22,180-186$.

${ }^{2}$ Atkinson, D.R., Casas, A., \& Abreu, J. (1992). Mexican-American acculturation, counselor ethnicity and cultural sensitivity, and perceived counselor competence. Journal of Counseling Psychology, 39(4), 515-520.

${ }^{1}$ Atkinson, D. R., Furlong, M. J., \& Poston, W. C. (1986). Afro-American preferences for counselor characteristics. Journal of Counseling Psychology, 33(3), 326-330.

Atkinson, D. R., \& Lowe, S. M. (1995). The role of ethnicity, cultural knowledge, and conventional techniques in counseling and psychotherapy. In J. G. Ponterotto, J. M. Casa, L. A. Suzuki, \& C. M. Alexander (Eds.), Handbook of multicultural counseling (pp. 387-414). Thousand Oaks, CA: Sage.

${ }^{2}$ Atkinson, D. R., Maruyama, M., \& Matsui, S. (1978). Effects of counselor race and counseling approach on Asian Americans' perceptions of counselor credibility and utility. Journal of Counseling Psychology, 25(1), 76-83.

${ }^{2}$ Atkinson, D. R., \& Matsushita, Y. J. (1991). Japanese-American acculturation, counseling style, counselor ethnicity, and perceived counselor credibility. Journal of Counseling Psychology, 38(4), 473-478.

${ }^{2}$ Atkinson, D. R., Ponce, F. Q., \& Martinez, F. M. (1984). Effects of ethnic, sex, and attitude similarity on counselor credibility. Journal of Counseling Psychology, 31(4), 588-590. 
${ }^{1}$ Atkinson, D. R., Poston, W. C., Furlong, M. J., \& Mercado, P. (1989). Ethnic group preferences for counselor characteristics. Journal of Counseling Psychology, $36(1), 68-72$.

${ }^{2}$ Atkinson, D. R., Winzelberg, A., \& Holland, A. (1985). Ethnicity, locus of control for family planning, and pregnancy counselor credibility. Journal of Counseling Psychology, 32(3), 417-421.

${ }^{2}$ Banks, W. M. (1972). The differential effects of race and social class in helping. Journal of Clinical Psychology, 28(1), 90-92.

${ }^{1}$ Banks, G., Berenson, B. G., \& Carkhuff, R. R. (1967). The effects of counselor race and training upon counseling process with Negro clients in initial interviews. Journal of Clinical Psychology, 23(1), 70-72.

Barak, A., \& LaCrosse, M. B. (1975). Multidimensional perception of counselor behavior. Journal of Counseling Psychology, 22, 471-476.

Begg, C. B. (1994). Publication bias. In H. Cooper \& L. V. Hedges (Eds.), The handbook of research synthesis (pp. 399-409). New York, NY: Russell Sage Foundation.

Benish, S. G., Quintana, S., \& Wampold, B. E. (2011). Culturally adapted psychotherapy and the legitimacy of myth: A direct-comparison meta-analysis. Journal of Counseling Psychology, 58, 279-289.

${ }^{1}$ Bennett, S. K., \& BigFoot-Sipes, D. S. (1991). American Indian and White college student preferences for counselor characteristics. Journal of Counseling Psychology, 38(4), 440-445. 
${ }^{2}$ Berg, J. H., \& Wright-Buckley, C. (1988). Effects of racial similarity and interviewer intimacy in a peer counseling analogue. Journal of Counseling Psychology, 35(4), 377-384.

${ }^{1}$ Bernstein, B. L., Wade, P., \& Hofmann, B. (1987). Students' race and preferences for counselor's race, sex, age, and experience. Journal of Multicultural Counseling and Development, 15(2), 60-70.

Berscheid, E., Dion, K., Walster, E., \& Walster, G. (1971). Physical attractiveness and dating choice: A test of the matching hypothesis. Journal of Experimental Social Psychology, 7(2), 173-189.

Betancourt, H., \& Lopez, S. R. (1995). The study of culture, ethnicity, and race in American psychology. In N.R. Goldberger \& J.B. Veroff (Eds.), The culture and psychology reader (pp. 87-107). New York: New York University Press.

${ }^{1}$ BigFoot-Sipes, D. S., Dauphinais, P., LaFromboise, T. D., Bennett, S. K., \& Rowe, W. (1992). American Indian secondary school students' preferences for counselors. Journal of Multicultural Counseling and Development, 20, 113-122.

${ }^{1}$ Bichsel, R. J., \& Mallinckrodt, B. (2001). Cultural commitment and the counseling preferences and counselor perceptions of Native American women. The Counseling Psychologist, 29, 858-881.

${ }^{3}$ Bryan, L. A., Dersch, C., Shumway, S., \& Arredondo, R. (2004). Therapy outcomes: Client perception and similarity with therapist view. The American Journal of Family Therapy, 32, 11-26. 
${ }^{2}$ Burkard, A. W., Juarez-Huffaker, M., \& Ajmere, K. (2003). White racial identity attitudes as a predictor of client perceptions of cross-cultural working alliances. Journal of Multicultural Counseling and Development, 31, 226-244.

${ }^{2}$ Burrell, L., \& Rayder, N. F. (1971). Black and white students' attitudes toward white counselors. Journal of Negro Education, 40(1), 48-52.

${ }^{2}$ Butler, T. (1980). A study of the nonlexical differential speech behavior of White clients when paired with Black versus White therapists for psychotherapy-like sessions. Unpublished doctoral dissertation. University of Maryland, College Park.

Byrne, D. (1971). The attraction paradigm. New York: Academic Press.

Campbell, D.T., \& Stanley, J.C. (1966). Experimental and quasi-experimental designs for research. Chicago, IL: Rand McNally.

${ }^{2}$ Carkhuff, R. R., \& Pierce, R. (1967). Differential effects of therapist race and social class upon patient depth of self-exploration in the initial clinical interview. Journal of Consulting Psychology, 31(6), 632-634.

${ }^{1}$ Cashwell, C. S., Shcherbakova, J., \& Cashwell, T. H. (2003). Effect of client and counselor ethnicity on preference for counselor disclosure. Journal of Counseling and Development, 81, 196-201.

Cates, J. T., Schaefle, S. E., Smaby, M. H., Maddux, C. D., \& LeBeauf, I. (2007). Comparing multicultural with general counseling knowledge and skill competency for students who completed counselor training. Journal of Multicultural Counseling and Development, 35, 26-39. 
${ }^{2}$ Chan, T. H. (1989). Asian and Caucasian Americans' perception of counseling: Acculturation and directiveness. Unpublished master thesis, Michigan State University, East Lansing.

${ }^{3}$ Chapman, C. R. (1999). Ethnic match and depression. (Unpublished doctoral dissertation). Fuller Theological Seminary, Pasadena, CA.

${ }^{2}$ Chin, J. M. (2005). The role of counselor ethnicity and racial attitudes in initial counselor effectiveness ratings by Asian American and Euro-American college students. Unpublished thesis, University of California, Riverside.

${ }^{3}$ Chinman, M. J., Rosenheck, R. A., \& Lam, J. A. (2000). Client-case manager racial matching in a program for homeless persons with serious mental illness. Psychiatric Services, 51(10), 1265-1272.

Choma, B. L., \& Hodson, G. (2008). And so the pendulum swings: A framework for conceptualizing the causes of prejudice. In M.A. Morrison \& T.G. Morrison (Eds.), The psychology of modern prejudice (pp. 1-25). New York, NY: Nova Science Publishers, Inc.

${ }^{2}$ Cimbolic, P. (1972). Counselor race and experience effects on Black clients. Journal of Consulting and Clinical Psychology, 39(2), 328-332.

${ }^{2}$ Cimbolic, P. (1973). T Group effects on Black clients' perceptions of counselors. Journal of College Student Personnel, 14(4), 296-302.

Cohen, J. (1988). Statistical power analysis for the behavioral sciences (2nd ed.). Hillsdale, NJ: Earlbaum. 
Coleman, H. L. K., Wampold, B. E., \& Casali, S. L. (1995). Ethnic minorities' ratings of ethnically similar and European American counselors: A meta-analysis. Journal of Counseling Psychology, 42(1), 55-64.

Cooper, H. (1998). Synthesizing research: A guide for literature reviews (3rd ed.). Thousand Oaks, CA: Sage.

Cooper, H., \& Hedges, L. V. (Eds.). (1994). The handbook of research synthesis. New York, NY: Russell Sage.

${ }^{1}$ Cosby, S. G. (1991). Factors influencing self-disclosure patterns of Black college students. (Unpublished doctoral dissertation). University of Rhode Island, Kingston.

Critcher, C., \& Dunning, D. (2009). Egocentric pattern projection: How implicit personality theories recapitulate the geography of the self. Journal of Personality and Social Psychology, 97(1), 1-16.

${ }^{2}$ Dalton, I. E. (2000). Acculturative stress, cultural content and race of the therapist: Its effects on African-American women's ratings of therapist credibility and competence. (Unpublished doctoral dissertation). Georgia State University, Atlanta.

Dauphinais, P., Dauphinais, L., \& Rowe, W. (1981). Effects of race and communication style on Indian perceptions of counselor effectiveness. Counselor Education and Supervision, 21(1), 72-80.

${ }^{3}$ Dembo, R., Ikle, D. N. \& Ciarlo, J. A. (1983). The influence of client-clinician demographic match on client treatment outcomes. Journal of Psychiatric Treatment and Evaluation, 5(1), 45-53. 
${ }^{3}$ Diaz-Vivar, N. (2003). Community mental health services as an intervention for ethnically diverse children and adolescents with behavioral problems. (Unpublished doctoral dissertation). University of La Verne, La Verne, CA.

Dovidio, J. (2001). On the nature of prejudice: The third wave. Journal of Social Issues, 57, 829-849.

Dovidio, J., Gaertner, S., Kawakami, K., \& Hodson, G. (2002). Why can’t we just get along? Interpersonal biases and interracial distrust. Cultural Diversity and Ethnic Minority Psychology, 8(2), 88-102.

Duval, S., \& Tweedie, R. (2000). A non-parametric "trim and fill" method of accounting for publication bias in meta-analysis. Journal of the American Statistical Association, 95, 89-98.

Ekehammar, B., \& Sidanius, J. (1982). Sex differences in sociopolitical attitudes: A replication and extension. British Journal of Social Psychology, 21(3), 249-257.

${ }^{2}$ Erdur, O., Rude, S., Baron, A., Draper, M., \& Shankar, L. (2000). Working alliance and treatment outcome in ethnically similar and dissimilar client-therapist pairings. Paper presented at the Research Consortium of Counseling \& Psychological Services in Higher Education, Austin, TX.

${ }^{3}$ Erdur, O., Rude, S. S., \& Baron, A. (2003). Symptom improvement and length of treatment in ethnically similar and dissimilar client-therapist pairings. Journal of Counseling Psychology, 50(1), 52-58.

${ }^{1}$ Esters, I., \& Ledoux, C. (2001). At-risk high school students' preferences for counselor characteristics. Professional School Counseling, 4(3), 165-170. 
${ }^{2}$ Ewing, T. N. (1974). Racial similarity of client and counselor and client satisfaction with counseling. Journal of Counseling Psychology, 21(5), 446-449.

Festinger, L. (1954). A theory of social comparison processes. Human Relations, 7, 117140.

Field, A. P. (2005). Is the meta-analysis of correlation coefficients accurate when population correlations vary? Psychological Methods, 10(4), 444-467.

${ }^{2,3}$ Fiorentine, R., \& Hillhouse, M. P. (1999). Drug treatment effectiveness and clientcounselor empathy: Exploring the effects of gender and ethnic congruency. Journal of Drug Issues, 29(1), 59-74.

Flaskerud, J. H. (1990). Matching client and therapist ethnicity, language, and gender: A review of research. Issues in Mental Health Nursing, 11, 321-336.

${ }^{3}$ Flaskerud, J. H., \& Hu L. (1994). Participation in and outcome of treatment for major depression among low income Asian-Americans, Psychiatry Research, 53, 289300.

${ }^{3}$ Flaskerud, J. H., \& Liu, P. Y. (1990). Influence of therapist ethnicity and language on therapy outcomes of southeast Asian clients. The International Journal of Social Psychology, 36(1), 18-29.

Flaskerud, J. H., \& Liu, P. Y. (1991). Effects of an Asian client-therapist language, ethnicity, and gender match on utilization and outcome of therapy. Community Mental Health Journal, 27(1), 31-42.

${ }^{2,3}$ Flicker, S. M. (2004). The relationship between ethnic matching, therapeutic alliance, and treatment outcome with Hispanic and Anglo adolescents in family therapy. (Unpublished doctoral dissertation). University of New Mexico, Albuquerque. 
${ }^{2}$ Fraga, E. D. (2003). The relationships among perceived client-counselor ethnic similarity, perceived client-counselor Hispanic cultural value similarity, and counseling process and outcome variables. Unpublished doctoral dissertation. University of California-Santa Barbara.

${ }^{1}$ Franco, J. N., \& LeVine, E. (1980). An analogue study of counselor ethnicity and client preference. Hispanic Journal of Behavioral Sciences, 2(2), 177-183.

${ }^{2}$ Fuertes, J. N., Stracuzzi, T. I., Bennett, J., Scheinholtz, J., Mislowack, A., Hersh, M., \& Cheng, D. (2006). Therapist multicultural competency: A study of therapy dyads. Psychotherapy: Theory, Research, Practice, Training, 43(4), 480-490.

${ }^{3}$ Fujino, D. C., Okazaki, S., \& Young, K. (1994). Asian-American women in the mental health system: An examination of ethnic and gender match between therapist and client. Journal of Community Psychology, 22, 164-176.

${ }^{2}$ Furlong, M. J., Atkinson, D. R., \& Casas, J. M. (1979). Effects of counselor ethnicity and attitudinal similarity on Chicano students' perceptions of counselor credibility and attractiveness. Hispanic Journal of Behavioral Sciences, 1(1), 41-53.

Gallo, J. J., Marino, S., Ford, D., \& Anthony, J. C. (1995). Filters on the pathway to mental health care, II. Sociodemographic factors. Psychological Medicine, 25, 1149-1160.

${ }^{2}$ Gamble, K. B. (2000). Portuguese-Americans and mental health treatment: Clienttherapist ethnic match, ethnic identity, and satisfaction with treatment. (Unpublished doctoral dissertation). Old Dominion University, Norfolk, VA. 
${ }^{1}$ Gamboa, A. M. (1971). Race and counselor climate as selected factors in the counselor preference of delinquent girls. (Unpublished doctoral dissertation). Ohio State University, Columbus.

${ }^{2,3}$ Gamst, G., Aguilar-Kitibutr, A., Herdina, A., Hibbs, S., Krishtal, E., Lee, R., Roberg, R., Ryan, E., Stephens, H., \& Martenson, L. (2003). Effects of racial match on Asian American mental health consumer satisfaction. Mental Health Services Research, 5(4), 197-208.

${ }^{3}$ Gamst, G., Dana, R. H., Der-Karabetian, A., \& Kramer, T. (2000). Ethnic match and client ethnicity effects on global assessment and visitation. Journal of Community Psychology, 28(5), 547-564.

${ }^{3}$ Gamst, G., Dana, R. H., Der-Karabetian, A., \& Kramer, T. (2001). Asian American mental health clients: Effects of ethnic match and age on global assessment and visitation. Journal of Mental Health Counseling, 23(1), 57-71.

${ }^{3}$ Gamst, G., Dana, R. H., Der-Karabetian, A., \& Kramer, T. (2004). Ethnic match and treatment outcomes for child and adolescent mental health center clients. Journal of Counseling \& Development, 82, 457-465.

${ }^{2}$ Gardner, W. E. (1972). The differential effects of race, education and experience in helping. Journal of Clinical Psychology, 28(1), 87-89.

${ }^{3}$ Geiger, L. A. (1992). Ethnic match and client characteristics as predictors of treatment outcome for anxiety disorders. (Unpublished doctoral dissertation). Fuller Theological Seminary, Pasadena, CA.

${ }^{2}$ Gilbert, Z. L. (1980). The effects of counselor gender, race and warmth and observer race and gender on measures of observer preference, attitudes and counseling 
seeking behavior. (Unpublished doctoral dissertation). University of Kentucky, Lexington.

${ }^{1}$ Gilsdorf, D. L. (1978). Counselor preference of Mexican-American, Black, and White community college concerns. Journal of Non-White Concerns, 6(4), 162-168.

${ }^{2}$ Gim, R. H., Atkinson, D. R., \& Kim, S. J. (1991). Asian-American acculturation, counselor ethnicity and cultural sensitivity, and ratings of counselors. Journal of Counseling Psychology, 38(1), 57-62.

Gleser, L. J., \& Olkin, I. (1994). Stochastically dependent effect sizes. In H. Cooper, L. V. Hedges, H. Cooper, \& L. V. Hedges (Eds.), The handbook of research synthesis (pp. 339-355). New York, NY US: Russell Sage Foundation.

${ }^{2}$ Goldberg, B., \& Tidwell, R. (1990). Ethnicity and gender similarity: The effectiveness of counseling for adolescents. Journal of Youth and Adolescence, 19(6), 589-603.

${ }^{1}$ Gomes, S. (2000). Factors affecting Asian Indian selection of psychotherapy: Therapist ethnicity and therapy modality. (Unpublished doctoral dissertation). The California School of Professional Psychology, San Diego.

${ }^{1}$ Gordon, M., \& Grantham, R. J. (1979). Helper preference in disadvantaged students. Journal of Counseling Psychology, 26(4), 337-343.

${ }^{2}$ Grantham, R. J. (1973). Effects of counselor sex, race, and language style on Black students in initial interviews. Journal of Counseling Psychology, 20(6), 553-559.

${ }^{1}$ Greene, C. J. (1982). A study of community-college students' initial counselor preferences based on the nature of the personal problem and on the age, ethnicity, and sex of the counselor and student. (Unpublished doctoral dissertation). The University of San Francisco, San Francisco, CA. 
${ }^{2}$ Greene, J. R. (1974). Interactive effects of counselor race and levels of functioning with client race and advantagement as measured by client self-exploration during the initial interview. (Unpublished doctoral dissertation). Georgia State University, Atlanta.

${ }^{3}$ Griffin, L. (2004) Effects of client-therapist ethnic match and client ethnicity on rehabilitation outcomes of chronically mentally ill clients. (Unpublished doctoral dissertation). University of La Verne, La Verne, CA.

Griffith, M. S., \& Jones, E. E. (1979). Race and psychotherapy: Changing perspectives. In J. M. Masserman (Ed.), Current psychiatric therapies (Vol. 18, pp. 225-235). New York, NY: Grune \& Stratton.

Griner, D., \& Smith, T. B. (2006). Culturally adapted mental health interventions: A meta-analytic review. Psychotherapy: Theory, Research, Practice, Training, 43(4), 531-548.

${ }^{3}$ Halliday-Boykins, C.A., Schoenwald, S.K., \& Letourneau, E.J.(2005). Caregivertherapist ethnic similarity predicts youth outcomes from an empirically based treatment. Journal of Consulting and Clinical Psychology, 73(5), 808-818.

Harrison, D. K. (1975). Race as a counselor-client variable in counseling and psychotherapy: A review of the research. The Counseling Psychologist, 5(1), 124133.

${ }^{1}$ Haviland, M. G., Horswill, R. K., O'Connell, J. J., \& Dynneson, V. V. (1983). Native American college students' preference for counselor race and sex and the likelihood of their use of a counseling center. Journal of Counseling Psychology, 30(2), 267-270. 
Hedges, L. V., \& Olkin, I. (1985). Statistical methods for meta-analysis. New York, NY: Academic Press.

${ }^{1,3}$ Heffernon, A., \& Bruehl, D. (1971). Some effects of race of inexperienced lay counselors on Black junior high school students. Journal of School Psychology, $9(1), 35-37$.

${ }^{1}$ Helms, J. E., \& Carter, R. T. (1991). Relationships of White and Black racial identity attitudes and demographic similarity to counselor preferences. Journal of Counseling Psychology, 38(4), 446-457.

${ }^{3}$ Hirokawa, G.M. (1992). The relationship of ethnic and sex match between client and therapist on treatment outcome and premature termination among Asian American adolescents. (Unpublished doctoral dissertation). California School of Professional Psychology - Los Angeles, Los Angeles.

${ }^{1}$ Hom, K. L. (1996). Investigating the influence of individualism-collectivism and acculturation on counselor preference and attitudes toward seeking counseling among Asian Americans. (Unpublished doctoral dissertation). Washington State University, Pullman.

${ }^{1}$ Jackson, G. G., \& Kirschner, S. A. (1973). Racial self-designation and preference for a counselor. Journal of Counseling Psychology, 20(6), 560-564.

${ }^{2}$ Jackson-Bailey, C. (2006). Black male college students' perceptions of counselor effectiveness: Using a culturally sensitive counseling approach. (Unpublished doctoral dissertation). University of Wisconsin-Milwaukee, Milwaukee.

${ }^{3}$ Jones, E. E. (1982). Psychotherapists' impressions of treatment outcome as a function of race. Journal of Clinical Psychology, 38(4), 722-731. 
${ }^{2}$ Kang, J. R. (1992). The effects of counselor ethnicity, counseling style, and acculturation on male Korean graduate students' perceptions of counselor effectiveness. (Unpublished doctoral dissertation). Indiana University, Bloomington.

Karlsson, R. (2005). Ethnic matching between therapist and patient in psychotherapy: An overview of findings, together with methodological and conceptual issues, Cultural Diversity and Ethnic Minority Psychology, 11(2), 113-129.

Kelly, T. A., \& Strupp, H. H. (1992). Patient and therapist values in psychotherapy: Perceived changes, assimilation, similarity, and outcome. Journal of Consulting and Clinical Psychology, 60(1), 34-40.

Kenny, D., \& West, T. (2010). Similarity and agreement in self- and other perception: A meta-analysis. Personality and Social Psychology Review, 14(2), 196-213.

${ }^{2}$ Kim, B. S. K. (2000). Asian American client adherence to Asian cultural values, counselor ethnicity, counselor expression of cultural values, and career counseling process and outcome. (Unpublished doctoral dissertation). University of California, Santa Barbara.

${ }^{3}$ Kim, B. S. K., Liang, C. T. H., \& Li, L. C. (2003). Counselor ethnicity, counselor nonverbal behavior, and session outcome with Asian American clients: Initial findings. Journal of Counseling \& Development, 81, 202-207.

${ }^{1}$ King, K. E. (1997). Therapist attitudes toward diversity: An exploration of factors which correlate with positive attitudes toward multiculturalism and women's equity. (Unpublished doctoral dissertation). Northeastern University, Boston, MA. 
${ }^{3}$ Kirkpatrick, K. (1992). The effect of ethnic match and client characteristics on premature termination, length of treatment, and global functioning of clients with major depression. (Unpublished doctoral dissertation). Fuller Theological Seminary, Pasadena, CA.

${ }^{2}$ Knipscheer, J. W. \& Kleber, R. J. (2004). A need for ethnic similarity in the therapistpatient interaction? Mediterranean migrants in Dutch mental-health care. Journal of Clinical Psychology, 60(6), 543-554.

${ }^{2}$ Knipscheer, J. W., \& Kleber, R. J. (2004). The importance of ethnic similarity in the therapist-patient dyad among Surinamese migrants in Dutch mental health care. Psychology and Psychotherapy: Theory, Research and Practice, 77(2), 273-278.

${ }^{3}$ Koch, E. R. (2004). Factors associated with treatment outcomes among Hispanic survivors of childhood sexual abuse. (Unpublished doctoral dissertation). Fuller Theological Seminary, Pasadena, CA.

Kohatsu, E. L., Dulay, M., Lam, C., Concepcion, W., Perez, P., Lopez, C., \& Euler, J. (2000). Using racial identity theory to explore racial mistrust and interracial contact among Asian Americans, Journal of Counseling \& Development, 78(3), 334-342.

${ }^{3}$ Krishtal, E. (2004). The effects of ethnicity and consumer-provider ethnic match on the quality of life among the chronically mentally ill. (Unpublished doctoral dissertation). University of La Verne, La Verne, CA.

${ }^{3}$ Kuipers, C. M. (1992). Ethnic match and client characteristics as predictors of treatment duration and outcome among schizophrenics. (Unpublished doctoral dissertation). Fuller Theological Seminary, Pasadena, CA. 
LaFromboise, T. D., \& Dixon, D. N. (1981). American Indian perception on trustworthiness in a counseling interview. Journal of Counseling Psychology, 28, 135-139.

Lambert, M. J., Burlingame, G. M., Umphress, V., Hansen, N. B., Vermeersch, D. A., Clouse, G. C., \& Yanchar, S. C. (1996). The reliability and validity of the Outcome Questionnaire. Clinical Psychology and Psychotherapy, 3, 249-258.

Lambert, M. J., Smart, D. W., Campbell, M. P., Hawkins, E. J., Harmon, C., \& Slade, K. L. (2006). Psychotherapy outcome, as measured by the OQ-45, in African American, Asian/Pacific Islander, Latino/a, and Native American clients compared with matched Caucasian clients. Journal of College Student Psychotherapy, 20(4), 17-29.

${ }^{1}$ Landrum, J. (1984). Comparison of minority and nonminority students' attitudes toward counseling-center services and perceived problem areas. (Unpublished doctoral dissertation). Michigan State University, East Lansing.

${ }^{2}$ Latham, P. A. (2000). Client and counselor factors affecting counseling expectations among Black students. (Unpublished doctoral dissertation). University of Massachusetts, Boston.

${ }^{2}$ Lee, D. Y., Sutton, R., France, H., \& Uhlemann, M. (1983). Effects of counselor race on perceived counseling effectiveness. Journal of Counseling Psychology, 30(3), 447-450.

Lee, K., Ashton, M. C., Pozzebon, J. A., Visser, B. A., Bourdage, J. S., \& Ogunfowora, B. (2009). Similarity and assumed similarity in personality reports of wellacquainted persons. Journal of Personality and Social Psychology, 96, 460-472. 
${ }^{3}$ Lee, R. E. (2004). The effects of ethnicity and consumer-provider ethnic match on child and adolescent clinical outcomes. (Unpublished doctoral dissertation). University of La Verne, La Verne, CA.

Lipsey, M. W., \& Wilson. D. B. (2001). Practical meta-analysis. Thousand Oaks, CA: Sage.

${ }^{1}$ Littrell, J. M., \& Littrell, M. A. (1982). American Indian and Caucasian students' preferences for counselors: Effects of counselor dress and sex. Journal of Counseling Psychology, 29(1), 48-57.

${ }^{2}$ Liu, H. S. (2003). Client's perception of seeking counseling as a function of counselor ethnicity, counselor acculturation, counselor gender, and client gender. (Unpublished doctoral dissertation). University of North Texas, Denton.

${ }^{1}$ Lopez, S. R., Lopez, A. A., \& Fong, K. T. (1991). Mexican Americans' initial preferences for counselors: The role of ethnic factors. Journal of Counseling Psychology, 38(4), 487-496.

${ }^{3}$ Lorefice, L. S., \& Borus, J. F. (1984). Consumer evaluation of a community mental health service, II: Perceptions of clinical care. American Journal of Psychiatry, 141(11), 1449-1452.

Lorion, R. P., \& Parron, D. L. (1985). Countering the countertransference: A strategy for treating the untreatable. In P. Pedersen (Ed.), Handbook of cross-cultural counseling and therapy (pp. 79-86). Westport, CT: Greenwood Press.

Lyons, L. (1996). The meta-analysis calculator [Computer software]. Manassas, VA: Author. 
Maramba, G. G., \& Nagayama Hall, G. C. (2002). Meta-analyses of ethnic match as a predictor of dropout, utilization, and level of functioning. Cultural Diversity and Ethnic Minority Psychology, 8(3), 290-297.

Marks, G., \& Miller, N. (1987). Ten years of research on the false-consensus effect: An empirical and theoretical review. Psychological Bulletin, 102(1), 72-90.

${ }^{1,2}$ Marquez, M. (2005). World view and ethnic match in multicultural counseling. (Unpublished doctoral dissertation). Washington State University, Pullman.

${ }^{3}$ Martin, T. W. (1994). Community mental health services for ethnic minority adolescents: A test of the cultural responsiveness hypothesis. (Unpublished doctoral dissertation). Fuller Theological Seminary. Pasadena, Ca.

${ }^{3}$ Mathews, C. A., Glidden, D., Murray, S., Forster, P., \& Hargreaves, W. A. (2002). The effect on treatment outcomes of assigning patients to ethnically focused inpatient psychiatric units. Psychiatric Services, 53(7), 830-835.

Matt, G. E., \& Navarro, A. M. (1997). What meta-analyses have and have not taught us about psychotherapy effects: A review and future directions. Clinical Psychology Review, 17, 1-32.

Mautlsby, M. C., Jr. (1982). A historical view of Blacks' distrust of psychiatry. In S.M. Turner \& R. T. Jones (Eds.), Behavior modification in Black populations (pp. 3955). New York, NY: Plenum.

${ }^{1}$ McGurk, W.T. (1976). Anglo and Puerto Rican client attitudes generated by varied interaction distances and counselor ethnicity in the dyadic counseling interaction. (Unpublished doctoral dissertation). University of Massachusetts, Amherst, MA. 
Mendelsohn, G. A., \& Geller, M. H. (1963). Effects of counselor-client similarity on the outcome of counseling. Journal of Counseling Psychology, 10(1), 71-77.

${ }^{2}$ Merluzzi, T. V., Merluzzi, B. H., \& Kaul, T. J. (1977). Counselor race and power base: Effects on attitudes and behavior. Journal of Counseling Psychology, 24(5), 430436.

Messer, S. B., \& Wampold, B. E. (2002). Let's face facts: Common factors are more potent than specific therapy ingredients. Clinical Psychology: Science and Practice, 9(1), 21-25.

Miller, N., \& Marks, G. (1982). Assumed similarity between self and other: Effect of expectation of future interaction with that other. Social Psychology Quarterly, 45(2), 100-105.

Møllersen, S., Sexton, H., \& Holte, A. (2009). Effects of client and therapist ethnicity and ethnic matching: A prospective naturalistic study of outpatient mental health treatment in Northern Norway. Nordic Journal of Psychiatry, 63(3), 246-255.

Morrison, M.A., \& Morrison, T.G. (Eds.) (2008). The psychology of modern prejudice. New York, NY: Nova Science Publishers, Inc.

${ }^{1}$ Morten, G. H. (1984). Racial self-labeling and preference for counselor race. Journal of Non-White Concerns, 12(3), 105-109.

${ }^{1}$ Morten, G. H., \& Atkinson, D. R. (1983). Minority identity development and preference for counselor race. Journal of Negro Education, 52(2), 156-161.

Mullen, B. (1989). Advanced BASIC meta-analysis. Hillside, NJ: Erlbaum.

${ }^{2}$ Murakawa, F. T. (1986). Effects of race and generation level on Asian American perceptions of therapist effectiveness and therapist preference. (Unpublished 
doctoral dissertation). California School of Professional Psychology, Los Angeles.

${ }^{3}$ Murphy, D. (2007). The effects of ethnic match and length of treatment on anger and aggression in male batterers. (Unpublished doctoral dissertation). University of La Verne, La Verne, CA.

${ }^{2,3}$ Murphy, M. J., Faulkner, R. A., \& Behrens, C. (2004). The effect of therapist-client racial similarity on client satisfaction and therapist evaluation of treatment. Contemporary Family Therapy, 26(3), 279-292.

Nagayama Hall, G. C. (2001). Psychotherapy research and ethnic minorities: Empirical, ethical, and conceptual issues. Journal of Counseling and Clinical Psychology, $69,502-510$.

Neville, H., Spanierman, L., \& Doan, B. (2006). Exploring the association between colorblind racial ideology and multicultural counseling competencies. Cultural Diversity and Ethnic Minority Psychology, 12, 275-290.

Newcomb, T. M. (1961). The acquaintance process. New York: Holt, Rinehart, and Winston.

${ }^{1} \mathrm{Ng}$, G.F. (2007). The relationship among perceived participant-counselor ethnic similarity, participant acculturation and enculturation levels, and participant preferences for counselor self-disclosure topics among Asian Americans. (Unpublished doctoral dissertation). University of California, Santa Barbara.

${ }^{1}$ Okerson, F. (1997). African American undergraduate students' willingness to selfdisclose to African American and European American religious and secular 
counselors: An experiment. (Unpublished doctoral dissertation). Loyola College, Baltimore, MD.

${ }^{2}$ Okonji, J. M. A., Ososkie, J. N., \& Pulos, S. (1996). Preferred style and ethnicity of counselors by African American males. Journal of Black Psychology, 22(3), 329339.

${ }^{3}$ Ortega, A. N., \& Rosenheck, R. (2002). Hispanic client-case manager matching: Differences in outcomes and services use in a program for homeless persons with severe mental illness. Journal of Nervous and Mental Disease, 190(5), 315-323.

Orwin, R. (1983). A fail-safe $\mathrm{N}$ for effect size in meta-analysis. Journal of Educational Statistics, 8(2), 157-159.

O’Sullivan, M. J., Peterson, P. D., Cox, G. B., \& Kirkeby, J. (1989). Ethnic populations: Community mental health services ten years later. American Journal of Community Psychology, 17, 17-30.

${ }^{3}$ Parker-Sloat, E. L. (2003). Client-therapist ethnicity and gender matching as predictors of length of treatment and goal completion at a practicum training clinic. (Unpublished doctoral dissertation). University of Miami, Coral Gables, FL.

${ }^{1}$ Petrossian, A. (2008). Characteristics of a counselor and client dyad that affect perceptions of counseling. (Unpublished doctoral dissertation). Fairleigh Dickinson University, Madison, NJ.

${ }^{2,3}$ Pierce, K. (1999). The effect of matching client and case manager on gender and race on outcomes of case management with the homeless mentally ill. Unpublished doctoral dissertation. University of Missouri - St. Louis, St. Louis. 
${ }^{1}$ Pinchot, N., Riccio, A. C., \& Peters, H. J. (1975). Elementary school students' and their parents' preferences for counselors. Counselor Education and Supervision, 15(1), 28-33.

${ }^{2,3} \mathrm{Pitt}, \mathrm{N}$. W. (1979). The effects of therapist-patient similarity on the therapist's level of accurate empathy and selected psychotherapy process and outcome criteria. (Unpublished doctoral dissertation). Temple University, Philadelphia, PA.

${ }^{2}$ Ponce, F. Q., \& Atkinson, D. R. (1989). Mexican-American acculturation, counselor ethnicity, counseling style, and perceived counselor credibility. Journal of Counseling Psychology, 36(2), 203-208

Ponterotto, J. G., Alexander, C., \& Hinkston, J. (1988). Afro-American preferences for counselor characteristics: A replication and extension. Journal of Counseling Psychology, 35, 175-182.

Ponterotto, J., Casas, M., Suzuki, L., \& Alexander, C. (Eds). (2009). Handbook of multicultural counseling. ( $3^{\text {rd }}$ ed). Thousand Oaks, CA: Sage.

Pope-Davis, D. B., Coleman, H. L. K., Liu, W., \& Toporek, R. (Eds.). (2003). Handbook of multicultural competencies. Thousand Oaks, CA: Sage.

${ }^{1}$ Proctor, E. K., \& Rosen, A. (1981). Expectations and preferences for counselor race and their relation to intermediate treatment outcomes. Journal of Counseling Psychology, 28(1), 40-46.

Qualls, R. C., Cox, M. B., \& Schehr, T. L. (1992). Racial attitudes on campus: Are there gender differences? Journal of College Student Development, 33(6), 524-530.

Quintana, S., \& Minami, T. (2006). Guidelines for meta-analyses of counseling psychology research. The Counseling Psychologist, 34(6), 839-877. 
${ }^{2}$ Ramos, L. P. (1981). The effects of ethnicity and language on Mexican American students' perceptions of counselors. Unpublished doctoral dissertation. Arizona State University, Tempe.

${ }^{2}$ Ramos-Sanchez, L. (2009). Counselor bilingual ability, counselor ethnicity, acculturation, and Mexican Americans' perceived counselor credibility. Journal of Counseling \& Development, 87(3), 311-318.

${ }^{1}$ Ramos-Sanchez, L., Atkinson, D. R., Fraga, E. D. (1999). Mexican American's bilingual ability, counselor bilingualism cues, counselor ethnicity, and perceived counselor credibility. Journal of Counseling Psychology, 46(1), 125-131.

${ }^{3}$ Reams, L. F. (1998). African-American families in psychotherapy: The effects of therapist race. (Unpublished doctoral dissertation). Wisconsin School of Professional Psychology, Milwaukee.

Regier, D. A., Farmer, M. E., Rae, D. S., Myers, J. K., Kramer, M., Robins, L. N., George, L. K., Karno, M., \& Locke, B. Z. (1993). One-month prevalence of mental disorders in the United States and sociodemographic characteristics: The Epidemiologic Catchment Area study. Acta Psychiatrica Scandinavica, 88, 3547.

${ }^{1}$ Riccio, A. C., \& Barnes, K. D. (1973). Counselor preferences of senior high school students. Counselor Education and Supervision, 13(1), 36-40.

${ }^{2,3}$ Ricker, M., Nystul, M., \& Waldo, M. (1999). Counselors' and clients' ethnic similarity and therapeutic alliance in time-limited outcomes of counseling. Psychological Reports, 84, 674-676. 
Ridley, C. R. (1984). Clinical treatment of nondisclosing Black client: A therapeutic paradox. American Psychologist, 39, 1234-1244.

Robbins, J. M., \& Krueger, J. I. (2005). Social projection to ingroups and outgroups: A review and meta-analysis. Personality and Social Psychology Review, 9(1), 3247.

Ross, L., Greene, D., \& House, P. (1977). The false consensus effect: An egocentric bias in social perception and attribution processes. Journal of Experimental Social Psychology, 13(3), 279-301.

${ }^{3}$ Russell, G. L., Fujino, D. C., Sue, S., Cheung, M. K., \& Snowden, L. R. (1996). The effects of therapist-client ethnic match in the assessment of mental health functioning. Journal of Cross-Cultural Psychology, 27(5), 598-615.

${ }^{2}$ Sanchez, A. R. (1986). Effect of cultural commitment, counseling approach, and counselor ethnicity on perceptions of the counselor. (Unpublished doctoral dissertation). University of California, Santa Barbara.

Sanchez, A. R., \& King, M. (1986). Mexican American's use of counseling services: Cultural and institutional factors. Journal of College Student Personnel, 27, 344349.

Sattler, J. M. (1977). The effects of therapist-client racial similarity. In A. S. Gurman \& M. Razin (Eds.) Effective psychotherapy: A handbook of research (pp. 252-290). New York, NY: Pergamon Press.

${ }^{2}$ Schaumann, E. M. (1997). The effects of racial identity attitudes on therapeutic alliance in cross-racial dyads. (Unpublished doctoral dissertation). The California Institute of Integral Studies, San Francisco. 
${ }^{2}$ Schoenwald, S. K., Halliday-Boykins, C. A., \& Henggeler, S. W. (2003). Client-level predictors of adherence to MST in community service settings. Family Process, 42(3), 345-359.

${ }^{1}$ Sharma, P. (1994). Asian Indian attitudes toward seeking professional psychological help. (Unpublished doctoral dissertation). University of Texas, Austin.

Shin, S., Chow, C., Camacho-Gonsalves, T., Levy, R. J., Allen, I. E., Leff, H., S. (2005). A meta-analytic review of racial-ethnic matching of African American and Caucasian American clients and clinicians. Journal of Counseling Psychology, 52(1), 45-56.

${ }^{1}$ Silver, C. (1972). Counselor-client compatibility: A comparison of dogmatism and race in inner-city college-bound client decision-making. (Unpublished doctoral dissertation). St. John's University, Queens, NY.

Simons, H. W., Berkowitz, N. N., \& Moyer, R. J. (1970). Similarity, credibility, and attitude change: A review and a theory. Psychological Bulletin, 73, 1-16.

${ }^{1}$ Singleton, D. E. (1976). Racial self-designation, self-disclosure and counselor preference. (Unpublished doctoral dissertation). George Washington University, Washington D.C.

${ }^{2}$ Sladen, B. J. (1982). Effects of race and socioeconomic status on the perception of process variables in counseling. Journal of Counseling Psychology, 29(6), 560566.

${ }^{2}$ Smith, J. R. (2001). The influence of upwardly mobile African American women's racial identity development on anticipated satisfaction of counseling services. (Unpublished doctoral dissertation). University of Cincinnati, $\mathrm{OH}$. 
Smith, T. B. (2009). Culturally congruent practices in counseling and psychotherapy: A review of research. In J. G. Ponterotto, J. M. Casas, L. A. Suzuki, \& C. M. Alexander (Eds.), Handbook of multicultural counseling. (3rd ed., pp. 439-450). Thousand Oaks, CA: Sage.

Smith, T. B., Constantine, M. G., Dunn, T. W., Dinehart, J. M., \& Montoya, J. A. (2006). Multicultural education in the mental health professions: A meta-analytic review. Journal of Counseling Psychology, 53(1), 132-145.

Smith, T. B., Domenech Rodríguez, M., \& Bernal, G. (2011). Culture. Journal of Clinical Psychology, 67(2), 166-175.

Snowden, L. R. (1999). African American service use for mental health problems. Journal of Community Psychology, 27, 303-313.

${ }^{3}$ Snowden, L. R., Hu, T., \& Jerrell, J. M. (1995). Emergency care avoidance: Ethnic matching and participation in minority-serving programs. Community Mental Health Journal, 31(5), 463-473.

${ }^{2}$ Speight, S. L. (1990). The working alliance and therapeutic outcome in cross-cultural counseling: A preliminary investigation. (Unpublished doctoral dissertation). The Ohio State University, Columbus.

${ }^{2}$ Stephens, H. L. (2004). Consumer perspective of multicultural competence (CPMC): Development of a scale. (Unpublished doctoral dissertation). University of La Verne, CA.

${ }^{3}$ Sterling, R. C., Gottheil, E., Weinstein, S. P., \& Serota, R. (1998). Therapist/patient race and sex matching: Treatment retention and 9-month follow-up outcome. Addiction, 93(7), 1043-1050. 
${ }^{3}$ Sterling, R. C., Gottheil, E., Weinstein, S. P., \& Serota, R. (2001). The effect of therapist/patient race- and sex-matching in individual treatment. Addiction, 96(7), 1015-1022.

${ }^{2}$ Stockton, N. J. (1978). A comparison of methods of increasing client self-disclosure in an analogue setting when counselor race is varied. (Unpublished doctoral dissertation). Indiana University, Bloomington.

${ }^{1}$ Stranges, R.J., \& Riccio, A.C. (1970). Counselee preferences for counselors: Some implications for counselor education. Counselor Education and Supervision, 10(1), 39-45.

Sue, D. W., Arredondo, P., \& McDavis, R. J. (1992). Multicultural competencies and standards: A call to the profession. Journal of Counseling and Development, 70, 477-486.

Sue, S. (1977). Community mental health services to minority groups: Some optimism and pessimism. American Psychologist, 32, 616-624.

Sue, S. (1988). Psychotherapeutic services for ethnic minorities: Two decades of research findings. American Psychologist, 43(4), 301-308.

Sue, S. (1998). In search of cultural competence in psychotherapy and counseling. American Psychologist, 53, 440-448.

${ }^{3}$ Sue, S., Fujino, D. C., Hu, L., Takeuchi, D. T., \& Zane, N. W. S. (1991). Community mental health services for ethnic minority groups: A test of the cultural responsiveness hypothesis. Journal of Consulting and Clinical Psychology, 59(4), $533-540$. 
Sue, S., \& Lam, A. G. (2002). Cultural and demographic diversity. In J. Norcross (Ed.), Psychotherapy relationships that work: Therapist contributions and responsiveness to patients. (pp. 401-422). New York, NY: Oxford.

Sue, S., \& Zane, N. (1987). The role of culture and cultural techniques in psychotherapy: A critique and reformulation. American Psychologist, 42(1), 37-45.

Sue. S., Zane, N., \& Young, K. (1994). Research on psychotherapy with culturally diverse populations. In A. E. Bergin \& S. L. Garfield (Eds.), Handbook of psychotherapy and behavioral change (pp. 783-820). New York: Wiley.

Sussman, L. K., Robins, L. N., \& Earls, F. (1987). Treatment-seeking for depression by Black and White Americans. Social Science Medicine, 24, 187-196.

Takeuchi, D. T., \& Cheung, M.-K. (1998). Coercive and voluntary referrals: How ethnic minority adults get into mental health treatment. Ethnicity \& Health, 3(3), 149158.

${ }^{2}$ Taylor, V. K. (1970). Black adults' perceptions of counselors within the counselor-client relationship. (Unpublished doctoral dissertation). The Ohio State University, Columbus.

${ }^{2}$ Tedeschi, G. J. (1993). Counselor and client variables and ratings of counselors by Chinese international students. (Unpublished doctoral dissertation). University of Missouri-Kansas City, Kansas City.

Tharp, R. G. (1991). Cultural diversity and treatment of children. Journal of Consulting and Clinical Psychology, 59(6), 799-812. 
${ }^{1}$ Thomas, H. A. (1980). Counselor age, race, and sex preferences of older clients. (Unpublished doctoral dissertation). George Washington University, Washington, D.C.

${ }^{2,3}$ Thompson, C. E., Worthington, R., \& Atkinson, D. R. (1994). Counselor content orientation, counselor race and Black women's cultural mistrust and selfdisclosures. Journal of Counseling Psychology, 41(2), 155-161.

${ }^{1}$ Thompson, R. A., \& Cimibolic, P. (1978). Black students' counselor preference and attitudes toward counseling center use. Journal of Counseling Psychology, 25(6), 570-575.

${ }^{2,3}$ Thompson, V. L. S. \& Alexander, H. (2006). Therapists' race and African American clients' reactions to therapy. Psychotherapy: Theory, Research, Practice, Training, 43(1), 99-110.

${ }^{2}$ Thorn, G. R. (1996). The relationship between working alliance, cross-cultural counseling competency, referral sources, and racial identity attitudes: Psychotherapy with African American males. (Unpublished doctoral dissertation). University of Nebraska, Lincoln.

1,2 Tien, J. L., \& Johnson, H. L. (1985). Black mental health client's preference for therapists: A new look at an old issue. International Journal of Social Psychiatry, $31(4), 258-266$.

${ }^{1}$ Turner, G. M., \& Manthei, R. J. (1986). Students' expressed and actual preferences for counsellor race and sex. International Journal for the Advancement of Counselling, 9, 351-362. 
Turner, R., Lloyd, D., \& Taylor, J. (2006). Physical disability and mental health: An epidemiology of psychiatric and substance disorders. Rehabilitation Psychology, 51(3), 214-223.

U.S. Surgeon General. (1999). Mental health: A report of the surgeon general. Rockville, MD: U.S. Department of Health and Human Services.

U.S. Surgeon General. (2001). Mental health: Culture, race, and ethnicity. A supplement to mental health: A report of the surgeon general. Rockville, MD: U.S. Department of Health and Human Services.

${ }^{2}$ Vail, A. (1978). Factors influencing lower-class black patients remaining in treatment. Journal of Consulting and Clinical Psychology, 46(2), 341.

${ }^{2,3}$ Vetter, H. (2003). Effects of ethnicity and consumer-provider ethnic match on adult client satisfaction with a community mental health center. (Unpublished doctoral dissertation). University of La Verne, La Verne, CA.

${ }^{2}$ Wade, P., \& Bernstein, B. L. (1991). Culture sensitivity training and counselor's race: Effects on Black female clients' perceptions and attrition. Journal of Counseling Psychology, 38(1), 9-15.

${ }^{2}$ Want, V., Parham, T. A., Baker R. C., \& Sherman, M. (2004). African American students' ratings of Caucasian and African American counselors varying in racial consciousness. Cultural Diversity and Ethnic Minority Psychology, 10(2), 123136.

${ }^{1,2,3}$ Warren, R. C., Jackson, A. M., Nugaris, J., \& Farley, G. K. (1973). Differential attitudes of Black and White patients toward treatment in a child guidance clinic. American Journal of Orthopsychiatry, 43(3), 384-393. 
${ }^{2}$ Watson, Z. E. P., \& Paradise, L. V. (1997). The relationship of the Black male client's status of racial identity, the counselor's race and psychotheoretical orientation to the client's perception of the counselor in therapy. Challenge: A Journal of Research on African American Men, 8(1), 27-44.

${ }^{3}$ Webster, J. M. (2000). Children with disruptive behavior: Treatment and child variables in a clinical population. Unpublished doctoral dissertation. University of Illinois at Chicago, Chicago.

${ }^{1}$ Wetsit, D. (1992). Counseling preferences of American Indian students at the University of Montana. (Unpublished doctoral dissertation). University of Montana, Missoula.

Whaley, A. L. (2001). Cultural mistrust and mental health services for African Americans: A review and meta-analysis. The Counseling Psychologist, 29(4), $513-531$.

${ }^{3}$ Wiess, R. (1996). Race and ethnicity: Differences in presenting problems and perceptions of treatment outcome among college students. Unpublished doctoral dissertation. Boston University, Boston, MA.

${ }^{2}$ Wintersteen, M. B., Mensinger, J. L., \& Diamond, G. S. (2005). Do gender and racial differences between patient and therapist affect therapeutic alliance and treatment retention in adolescents? Professional Psychology: Research and Practice, 36(4), 400-408.

${ }^{1}$ Wolkon, G. H., Moriwaki, S., \& Williams, K. J. (1973). Race and social class as factors in the orientation toward psychotherapy. Journal of Counseling Psychology, 20(4), 312-316. 
${ }^{2}$ Womack, W. M., \& Wagner, N. N. (1967). Negro interviewers and white patients. Archives of General Psychiatry, 16(6), 685-692.

${ }^{2}$ Woods, E., \& Zimmer, J. M. (1976). Racial effects in counseling-like interviews: An experimental analogue. Journal of Counseling Psychology, 23(6), 527-531.

${ }^{2}$ Wright, W. (1971). Relationships of trust and racial perceptions toward therapist-client conditions during counseling. Journal of Negro Education, 44(2), 161-169.

Wu, I. H., \& Windle, C. (1980). Ethnic specificity in the relative minority use and staffing of community mental health centers. Community Mental Health Journal, 16(2), 156-168.

${ }^{3}$ Yeh, M., Eastman, K., \& Cheung, M. K. (1994). Children and adolescents in community health centers: Does the ethnicity or the language of the therapist matter? Journal of Community Psychology, 22, 153-163.

${ }^{3}$ Yeh, M., Takeuchi, D. T., \& Sue, S. (1994). Asian-American children treated in the mental health system: A comparison of parallel and mainstream outpatient service centers. Journal of Clinical Child Psychology, 23(1), 5-12.

${ }^{2}$ Zane, N., Sue, S., Chang, J., Huang, L., Huang, J., Lowe, S., Srinivasan, S., Chun, K., Kurasaki, K., \& Lee, E. (2005). Beyond ethnic match: Effects of client-therapist cognitive match in problem perception, coping orientation, and therapy goals on treatment outcomes. Journal of Community Psychology, 33(5), 569-585.

${ }^{3}$ Ziguras, S. J., Klimidis, S., Lambert, T. J. R., \& Jackson, A. C. (2001). Determinants of anti-psychotic medication compliance in a multicultural population. Community Mental Health Journal, 37(3), 273-283. 
Table 1

Study and Participant Characteristics by Study Type

\begin{tabular}{|c|c|c|c|}
\hline Variable & $\begin{array}{c}\text { Preferences } \\
k=52\end{array}$ & $\frac{\text { Perceptions }}{k=81}$ & $\frac{\text { Outcomes }}{k=53}$ \\
\hline \multicolumn{4}{|l|}{ Study Characteristics } \\
\hline Median number of participants & 123 & 89 & 326 \\
\hline Median year of publication & 1986 & 1991 & 1999 \\
\hline Unpublished/dissertations (\%) & 35 & 40 & 40 \\
\hline \multicolumn{4}{|l|}{ Research design } \\
\hline Surveys/analogue studies (\%) & 88 & 39 & 0 \\
\hline Archival studies (\%) & 0 & 0 & 43 \\
\hline Experimental $(\%)$ & 0 & 8 & 2 \\
\hline Group comparisons $(\%)$ & 8 & 49 & 43 \\
\hline Other $(\%)$ & 4 & 4 & 12 \\
\hline \multicolumn{4}{|l|}{ Participants' characteristics } \\
\hline Average age & 24 & 25 & 30 \\
\hline Average years of education & 13 & 13 & 11 \\
\hline$\%$ Female & 56 & 55 & 52 \\
\hline$\%$ Asian American & 9 & 15 & 19 \\
\hline$\%$ African American & 35 & 41 & 29 \\
\hline$\%$ Hispanic/Latino(a) American & 17 & 15 & 20 \\
\hline$\%$ White/European American & 27 & 24 & 28 \\
\hline$\%$ Other & 12 & 5 & 4 \\
\hline
\end{tabular}


Table 2

Weighted Average Effect Size Differences Across Participant Race by Study Type.

$\begin{array}{llllll}\text { Study Type / Race } & Q & p & d & 95 \% \text { CI } & \text { k }\end{array}$

$\begin{array}{lll}\text { Preferences } & 9.1 & .03\end{array}$

$\begin{array}{lccc}\text { Asian American } & .28 & {[-.23, .80]} & 6 \\ \text { Black/African American } & .88 & {[.60,1.2]} & 22 \\ \text { Hispanic/Latino(a) American } & .62 & {[.21,1.0]} & 10 \\ \text { White/European American } & .26 & {[-.09, .61]} & 13\end{array}$

$\begin{array}{lll}\text { Perceptions } & 11.8 \quad 008\end{array}$

Asian American

$.56 \quad[.10,1.0] \quad 11$

Black/African American

$.59 \quad[.30, .88] \quad 28$

Hispanic/Latino(a) American

$\begin{array}{lll}-.11 & {[-.53, .30]} & 13\end{array}$

White/European American

$-.08 \quad[-.50, .35] \quad 13$

$\begin{array}{lll}\text { Outcomes } & 9.9 & .02\end{array}$

$\begin{array}{lccc}\text { Asian American } & .11 & {[-.01, .23]} & 17 \\ \text { Black/African American } & .19 & {[.08, .30]} & 23 \\ \text { Hispanic/Latino(a) American } & -.04 & {[-.15, .08]} & 18 \\ \text { White/European American } & .01 & {[-.10, .12]} & 17\end{array}$

Note. $Q=$ an index of between-group differences. $d=$ random effects weighted standardized mean difference; the effect size. $\mathrm{k}=$ number of effect sizes included in the analysis. 
Table 3

Random Effects Weighted Correlations of Effect Sizes with Study Year and Sample Characteristics by Study Type

\begin{tabular}{lcccccccc}
\hline & \multicolumn{2}{c}{ Client Preferences } & & \multicolumn{2}{c}{ Client Perceptions } & & \multicolumn{2}{c}{ Client Outcomes } \\
\cline { 2 - 5 } Variable & $r$ & $\mathrm{k}$ & & $r$ & $\mathrm{k}$ & & $r$ & $\mathrm{k}$ \\
\hline Year of study publication & $-.29^{*}$ & 52 & & -.08 & 81 & & -.21 & 53 \\
Participant mean age & -.07 & 29 & -.03 & 48 & & .05 & 33 \\
Participant mean birth year & & -.24 & 29 & -.01 & 48 & -.16 & 33 \\
Participant mean education & .01 & 51 & -.03 & 79 & .03 & 47 \\
\% Female participants & -.19 & 51 & -.11 & 74 & .09 & 47 \\
\hline
\end{tabular}

Note: $* \mathrm{p}<.05 ; \mathrm{k}=$ number of studies included in the analysis.

${ }^{a}$ Year of study minus average age of clients at time of study (to estimate cohort effects). 